\title{
Experimental
}

All reagents used were obtained from commercial suppliers and were used as received, without further purification, while solvents were dried via passage over activated alumina prior to use. The synthesis of 1 was as described previously. [1] 4-(11-bromoundecyloxy)-4'-cyanobiphenyl was prepared as described previously. [2]

Reactions were monitored by thin layer chromatography (TLC) using an appropriate solvent system. Silica coated aluminium TLC plates used were purchased from Merck (Kieselgel 60 F-254) and visualised using either UV light ( $254 \mathrm{~nm}$ and $365 \mathrm{~nm}$ ), or by oxidation with either iodine or potassium permanganate solution. Yields refer to chromatographically and spectroscopically ( ${ }^{1} \mathrm{H}$ and $\left.{ }^{19} \mathrm{~F} \mathrm{NMR}\right)$ homogenous material. NMR spectra were recorded on a JEOL ECX spectrometer operating at 400 $\mathrm{MHz}\left({ }^{1} \mathrm{H}\right), 100.5 \mathrm{MHz}\left({ }^{13} \mathrm{C}\right)$ or $376.4 \mathrm{MHz}\left({ }^{19} \mathrm{~F}\right)$, with the residual protic solvent used as the internal standard for ${ }^{1} \mathrm{H}$ and ${ }^{13} \mathrm{C}$ spectra, while ${ }^{19} \mathrm{~F}$ were unreferenced. FTIR spectroscopy was performed using a Shimadzu IR Prestige-21 with Specac Golden Gate diamond ATR IR insert. The ATR stage was flushed with dry nitrogen during use to eliminate peaks resulting from atmospheric water and $\mathrm{CO}_{2}$. Mass spectra were recorded on a Bruker micrOTOF MS-Agilent series 1200LC spectrometer. Highperformance liquid chromatography was performed on a Shimadzu Prominence modular HPLC system comprising an LC-20A quaternary solvent pump, DGU-20A 5 and DGU-20B solvent degassers, a SIL$20 \mathrm{~A}$ autosampler, a CBM-20A communication bus, a CTO-20A column oven, and a SPD-20A dual wavelength UV-vis detector. The column used was a Discovery HS reverse phase (C18) HPLC column with a $5 \mu \mathrm{m}$ particle size, an internal diameter of $10 \mathrm{~mm}$ and a length of $250 \mathrm{~mm}$. Polarised optical microscopy was performed on a Zeiss Axioskop 40Pol microscope using a Mettler FP82HT hotstage controlled by a Mettler FP90 central processor. Photomicrographs were captured with aid of an InfinityX-21 MP digital camera. Differential scanning calorimetry was performed on a Mettler DSC822e fitted with an autosampler operating with Mettler Stare software and calibrated before use each day using an indium standard (onset $=156.55 \pm 0.2{ }^{\circ} \mathrm{C}, \Delta \mathrm{H}=28.45 \pm 0.40 \mathrm{Jg}^{-1}$ ) under an atmosphere of dry nitrogen. Small angle X-ray diffraction was performed using a Bruker D8 Discover equipped with a temperature controlled, bored graphite rod furnace, custom built at the University of York. Samples were filled into $1 \mathrm{~mm}$ capillary tubes and aligned magnetically (1T field). Diffraction patterns were collected as a function of temperature and the data processed using Bruker DIFFRAC.SUITE EVA software. Computational chemistry was performed using the using Gaussian G09 revision d01 on the York Advanced Research Computing Cluster (YARCC) as described in the text. [3] 


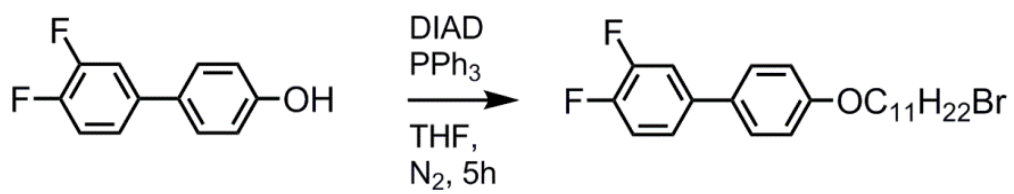

\section{3',4'-Difluoro-4-(11-bromoundecyloxy)biphenyl (i3)}

To a solution of 3,4-difluoro-4'-hydroxybiphenyl $(2.0 \mathrm{~g}, 9.71 \mathrm{mmol})$, 11-bromoundecanol $(2.7 \mathrm{~g}, 10.68$ $\mathrm{mmol})$ and triphenylphosphine $(2.5 \mathrm{~g}, 9.71 \mathrm{mmol})$ in anhydrous THF $(25 \mathrm{ml})$ under an atmosphere of dry nitrogen was added DIAD $(1.9 \mathrm{~g}, 1.91 \mathrm{ml}, 9.71 \mathrm{mmol})$ dropwise over a period of 5 minutes. The reaction solution was stirred until complete consumption of i1, as evidenced by TLC. Once the reaction was complete, the solvent was removed in vacuo and the crude residue purified by flash chromatography over silica gel with 2:1 DCM/petroleum ether as the eluent. The isolated material was then recrystallised from toluene, affording the target compound as fine white crystals.

Yield: $3 \mathrm{~g}(70 \%)$

${ }^{1} \mathrm{H}$ NMR $\left(\mathrm{CDCl}_{3}\right): 1.15-1.55\left(14 \mathrm{H}, \mathrm{m}, \mathrm{CH}_{2}-\left(\mathrm{CH}_{2}\right)_{7}-\mathrm{CH}_{2}-\right), 1.66-1.81\left(4 \mathrm{H}, \mathrm{m},-\mathrm{CH}_{2}-\mathrm{CH}_{2}-\left(\mathrm{CH}_{2}\right)_{7}-\mathrm{CH}_{2}-\right.$ $\left.\mathrm{CH}_{2}-\right), 3.31\left(2 \mathrm{H}, \mathrm{t}, \mathrm{J}=7.0 \mathrm{~Hz}, \mathrm{CH}_{2}-\mathrm{CH}_{2}-\mathrm{Br}\right), 3.88\left(2 \mathrm{H}, \mathrm{t}, \mathrm{J}=7.0 \mathrm{~Hz}, \mathrm{CH}_{2}-\mathrm{CH}_{2}-\mathrm{OAr}\right), 6.86(2 \mathrm{H}, \mathrm{ddd}, J=$ $2.1 \mathrm{~Hz}, J=3.1 \mathrm{~Hz}, J=8.5 \mathrm{~Hz}, \operatorname{ArH}), 7.04-7.17(2 \mathrm{H}, \mathrm{m}, \operatorname{ArH}), 7.22(1 \mathrm{H}, \mathrm{ddd}, J=2.1 \mathrm{~Hz}, J=4.3 \mathrm{~Hz}, J=$ $7.6 \mathrm{~Hz}, \operatorname{ArH}), 7.33(2 \mathrm{~h}, \mathrm{ddd}, J=2.1 \mathrm{~Hz}, J=3.1 \mathrm{~Hz}, J=8.5 \mathrm{~Hz}, \mathrm{ArH})$

19F NMR (CDCl $)$ ): -141.35 (1F, m, $\mathrm{ArF}),-137.77(1 \mathrm{~F}, \mathrm{~m}, \mathrm{ArF})$

FT-IR (cm-1): 721, 750, 802, 835, 883, 916, 962, 1010, 1042, 1100, 1137, 1166, 1240, 1278, 1296, 1309, 1503, 1602, 1737, 2846, 2916 
<smiles>Oc1ccc(-c2cc(F)c(F)c(F)c2)cc1</smiles><smiles>Fc1cc(-c2ccc(OCCBr)cc2)cc(F)c1F</smiles>

\section{3',4',5'-Trifluoro-4-(11-bromoundecyloxy)biphenyl (i4)}

Quantities used: 3,4,5-difluoro-4'-hydroxybiphenyl (1 g, 4.464 mmol), 11-bromoundecanol (1.23 g, 4.91 mmol) and triphenylphosphine (1.17 g, $4.464 \mathrm{mmol})$ DIAD (901 mg, $878 \mu \mathrm{l}, 4.464 \mathrm{mmol}$ ), anhydrous THF $(10 \mathrm{ml})$. The experimental procedure was as described for the synthesis of $\mathbf{i} 3$, with the title compound obtained via flash chromatography with 2:1 DCM/petroleum ether as the eluent, followed by recrystallisation from toluene, yielding the title compound as fine white crystals.

Yield: $1.4 \mathrm{~g}(68 \%)$

${ }^{1} \mathrm{H}$ NMR $\left(\mathrm{CDCl}_{3}\right): 1.25-1.45\left(14 \mathrm{H}, \mathrm{m}, \mathrm{CH}_{2}-\left(\mathrm{CH}_{2}\right)_{7}-\mathrm{CH}_{2}-\right), 1.71-1.84\left(4 \mathrm{H}, \mathrm{m},-\mathrm{CH}_{2}-\mathrm{CH}_{2}-\left(\mathrm{CH}_{2}\right)_{7}-\mathrm{CH}_{2}-\right.$ $\left.\mathrm{CH}_{2}-\right), 3.36\left(2 \mathrm{H}, \mathrm{t}, J=6.4 \mathrm{~Hz}, \mathrm{CH}_{2}-\mathrm{CH}_{2}-\mathrm{Br}\right), 3.93\left(2 \mathrm{H}, \mathrm{t}, J=6.4 \mathrm{~Hz}, \mathrm{CH}_{2}-\mathrm{CH}_{2}-\mathrm{OAr}\right), 6.90$ (2H, ddd, $J=$ $2.1 \mathrm{~Hz}, J=3.1 \mathrm{~Hz}, J=8.9 \mathrm{~Hz}, \operatorname{ArH}), 7.08(2 \mathrm{H}, \mathrm{dddd}, J=2.8 \mathrm{~Hz}, J=4.3 \mathrm{~Hz}, J=7.6 \mathrm{~Hz}, J=8.9 \mathrm{~Hz}$, $\operatorname{ArH}), 7.36(2 \mathrm{H}, \mathrm{ddd}, J=2.1 \mathrm{~Hz}, J=3.1 \mathrm{~Hz}, J=8.9 \mathrm{~Hz}, \operatorname{ArH})$,

19F NMR $\left(\mathrm{CDCl}_{3}\right):-163.8(1 \mathrm{~F}, \mathrm{tt}, J=6.9 \mathrm{~Hz}, J=20.7 \mathrm{~Hz}),-134.42(2 \mathrm{~F}$, dddd, $J=4.6 \mathrm{~Hz}, J=8.0 \mathrm{~Hz}, J=$ $9.2 \mathrm{~Hz}, J=20.7 \mathrm{~Hz})$

FT-IR (cm-1): 682, 723, 736, 765, 810, 840, 894, 910, 966, 1002, 1020, 1180, 1217, 1261, 1315, 1413, $1469,1494,1764,2850,2920$ 


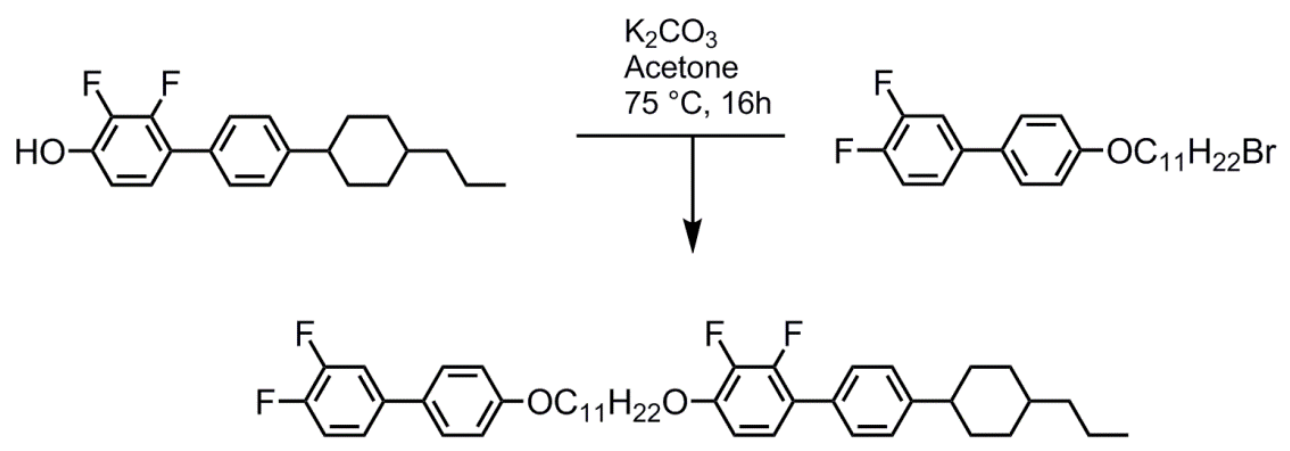

4-((11-((3',4'-Difluoro-[1,1'-biphenyl]-4-yl)oxy)undecyl)oxy)-2,3-difluoro-4'-(4-propylcyclohexyl)$1,1^{\prime}$-biphenyl (2)

Quantities used: i3 (220 mg, $0.501 \mathrm{mmol})$, 2,3-difluoro-4'-(4-propylcyclohexyl)-[1,1'-biphenyl]-4-ol (220 $\mathrm{mg}, 0.666 \mathrm{mmol})$, potassium carbonate $(220 \mathrm{mg}, 1.59 \mathrm{mmol})$, potassium iodide $(250 \mathrm{mg})$, acetone (3 $\mathrm{ml}$ ). The experimental procedure was as described for the synthesis of i3, with the title compound obtained via flash chromatography with 1:1 DCM/hexane as the eluent, followed by recrystalisation of the title compound from ethanol, giving the target material as colourless plates.

Yield: $360 \mathrm{mg}(95 \%)$

${ }^{1} \mathrm{H} \mathrm{NMR}\left(\mathrm{CDCl}_{3}\right): 0.83\left(3 \mathrm{H}, \mathrm{t}, \mathrm{J}=7.3 \mathrm{~Hz}, \mathrm{CH}_{3}-\mathrm{CH}_{2}-\right), 0.93-1.47(22 \mathrm{H}, \mathrm{m}), 1.69-1.89(8 \mathrm{H}, \mathrm{m}), 2.43$ $(1 \mathrm{H}, \mathrm{tt}, J=3.7 \mathrm{~Hz}, J=12.2 \mathrm{~Hz}, \mathrm{Ar}-\mathrm{CyH}), 3.91\left(2 \mathrm{H}, \mathrm{t}, J=6.4 \mathrm{~Hz}, \mathrm{CH}_{2} \mathrm{OAr}\right), 3.99(2 \mathrm{H}, \mathrm{t}, J=6.4 \mathrm{~Hz}$, $\left.\mathrm{CH}_{2} \mathrm{OAr}\right), 6.70(1 \mathrm{H}, \mathrm{ddd}, J=1.8 \mathrm{~Hz}, J=7.6 \mathrm{~Hz}, J=8.5 \mathrm{~Hz}, \mathrm{ArH}), 6.88(2 \mathrm{H}, \mathrm{ddd}, J=2.1 \mathrm{~Hz}, J=3.1 \mathrm{~Hz}$, $J=8.9 \mathrm{~Hz}, \operatorname{ArH}), 7.00(1 \mathrm{H}, \mathrm{dt}, J=2.4 \mathrm{~Hz}, J=8.5 \mathrm{~Hz}, \mathrm{ArH}), 7.06-7.22(4 \mathrm{H}, \mathrm{m}, \mathrm{ArH}), 7.25(1 \mathrm{H}, \mathrm{ddd}, J=$ $2.1 \mathrm{~Hz}, \mathrm{~J}=7.6 \mathrm{~Hz}, \mathrm{~J}=11.9 \mathrm{~Hz}, \mathrm{ArH}), 7.33-7.37(2 \mathrm{H}, \mathrm{m}, \mathrm{ArH})$

${ }^{13} \mathrm{C} \mathrm{NMR}\left(\mathrm{CDCl}_{3}\right): 14.39,20.01,25.84,26.00,29.12,29.22,29.27,29.34,29.45,29.47,29.49,33.51$, $34.25,36.98,36.69,44.30,68.06,69.79,109.43(\mathrm{~d}, J=2.9 \mathrm{~Hz}), 114.86,116.44$ (dd, $J=17.3 \mathrm{~Hz}, J=$ $196.5 \mathrm{~Hz}$ ), $122.30-122.48(\mathrm{~m}), 122.94$ (d, $J=10.5 \mathrm{~Hz}$ ), 123.44 (t, $J=3.8 \mathrm{~Hz}$ ), 127.00, 127.90, 128.55 (d, $J=2.9 \mathrm{~Hz}$ ), 131.36, 132.32, 138.00 (dd, $J=3.8 \mathrm{~Hz}, J=5.8 \mathrm{~Hz}$ ), 141.80 (dd, $J=12.3 \mathrm{~Hz}, J=247.3$ $\mathrm{Hz}$ ), 147.37 (d, $J=1.9 \mathrm{~Hz}$ ), 147.51, 147.61, 149.47 (dd, $J=12.5 \mathrm{~Hz}, J=247.3 \mathrm{~Hz}$ ), 150.04 (d, J = 11.5 $\mathrm{Hz}$ ), $150.48(\mathrm{dd}, J=12.5 \mathrm{~Hz}, J=247.3 \mathrm{~Hz}), 159.04$

19F NMR (CDCl $)$ ): -158.84 (1F, ddd, $J=2.3 \mathrm{~Hz}, J=4.6 \mathrm{~Hz}, J=19.5 \mathrm{~Hz}, \operatorname{ArF}),-141.83(1 \mathrm{~F}, \mathrm{dt}, J=8.0$ $\mathrm{Hz}, J=19.5, \operatorname{ArF}),-141.34(1 \mathrm{~F}, \mathrm{~m}, \mathrm{ArF}),-137.75(1 \mathrm{~F}, \mathrm{ddd}, J=8.0 \mathrm{~Hz}, J=11.5 \mathrm{~Hz}, J=20.7 \mathrm{~Hz}, \operatorname{ArF})$

FT-IR (cm-1): 692, 723, 775, 800, 839, 894, 962, 1074, 1105, 1163, 1217, 1228, 1294, 1365, 1471 , $1558,1739,2848,2918,2970$ 
MS (ESI+): $727.3511\left(\mathrm{C}_{44} \mathrm{H}_{52} \mathrm{~F}_{4} \mathrm{KO}_{2}, \mathrm{M}+\mathrm{K}\right), 711.8801\left(100 \%, \mathrm{C}_{44} \mathrm{H}_{52} \mathrm{~F}_{4} \mathrm{NaO}_{2}, \mathrm{M}+\mathrm{Na}\right.$, calc. for $\left.\mathrm{C}_{44} \mathrm{H}_{52} \mathrm{~F}_{4} \mathrm{NaO}_{2} 711.8808\right)$

Assay (HPLC, C18, 230/265 nm): 99.6\%
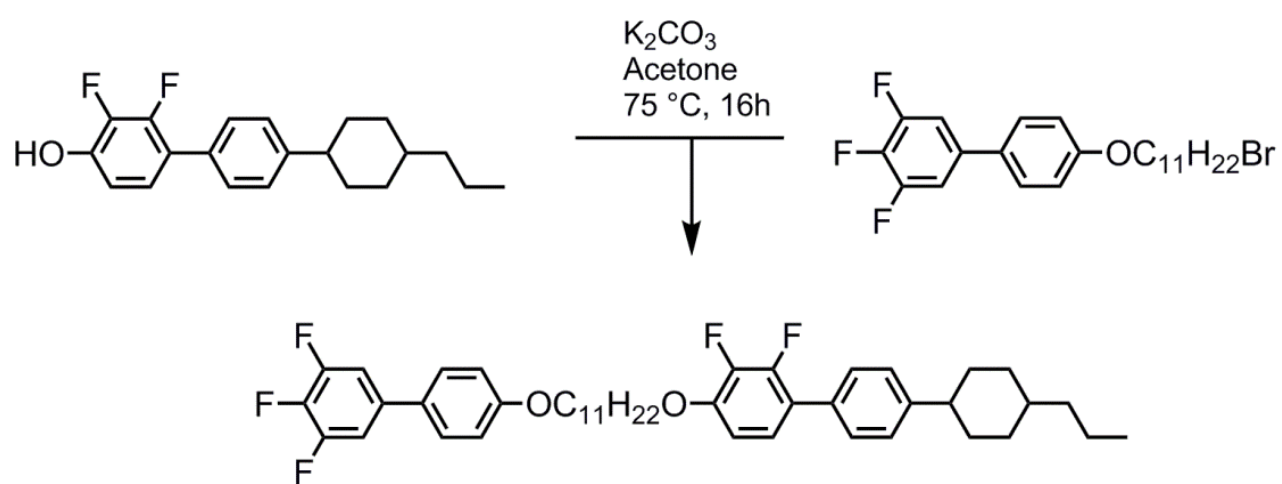

\section{4-((11-((3',4',5'-Trifluoro-[1,1'-biphenyl]-4-yl)oxy)undecyl)oxy)-2,3-difluoro-4'-(4- propylcyclohexyl)-1,1'-biphenyl (3)}

A suspension of i4 (300 mg, $0.656 \mathrm{mmol}), 2,3-$ difluoro-4'-(4-propylcyclohexyl)-[1,1'-biphenyl]-4-ol (238 $\mathrm{mg}, 0.722 \mathrm{mmol})$, potassium carbonate $(181 \mathrm{mg}, 1.31 \mathrm{mmol})$ and potassium iodide $(1 \mathrm{~g})$ in acetone (10 $\mathrm{ml}$ ) was heated under reflux with vigorous stirring for $24 \mathrm{~h}$. The suspension was cooled, filtered and the solvent removed in vacuo. The obtained residue was subjected to purification by flash chromatography with 1:1 DCM/hexane as the eluent, followed by recrystallisation of the title compound from ethanol, giving the target material as colourless plates.

Yield: $410 \mathrm{mg}(88 \%)$

${ }^{1} \mathrm{H} \operatorname{NMR}\left(\mathrm{CDCl}_{3}\right): 0.89\left(3 \mathrm{H}, \mathrm{t}, \mathrm{J}=6.9 \mathrm{~Hz}, \mathrm{CH}_{3}-\mathrm{CH}_{2}\right), 0.98-1.12\left(2 \mathrm{H}, \mathrm{m},-\mathrm{CH}_{2}-\mathrm{CH}_{2}-\mathrm{CH}_{3}\right), 1.15-1.54$ $\left(21 \mathrm{H}, \mathrm{m},-\mathrm{CH}_{2^{-}}+\mathrm{CyH}\right), 1.73-1.96\left(8 \mathrm{H}, \mathrm{m},-\mathrm{CH}_{2^{-}}+\mathrm{CyH}\right), 2.48(1 \mathrm{H}, \mathrm{tt}, J=3.2 \mathrm{~Hz}, J=11.9 \mathrm{~Hz}, \mathrm{CyH})$, $3.97\left(2 \mathrm{H}, \mathrm{t}, J=6.9 \mathrm{~Hz}, \mathrm{ArOCH}_{2-}\right), 4.04\left(2 \mathrm{H}, \mathrm{t}, J=6.9 \mathrm{~Hz}, \mathrm{ArOCH}_{2}-\right), 6.76(1 \mathrm{H}, \mathrm{dt}, J=1.8 \mathrm{~Hz}, J=8.2$ $\mathrm{Hz}, \operatorname{ArH}), 6.94(2 \mathrm{H}, \mathrm{ddd}, J=1.8 \mathrm{~Hz}, J=3.2 \mathrm{~Hz}, J=8.7 \mathrm{~Hz}, \operatorname{ArH}), 7.02-7.16(3 \mathrm{H}, \mathrm{m}, \operatorname{ArH}), 7.23-7.28$ $(2 \mathrm{H}, \mathrm{m}, \mathrm{ArH}), 7.36-7.44(4 \mathrm{H}, \mathrm{m}, \mathrm{ArH})$

${ }^{13} \mathrm{C}$ NMR $\left(\mathrm{CDCl}_{3}\right): 14.40,20.02,25.85,26.00,29.16,29.20,29.27,29.34,29.45,29.47,29.49,33.53$, 34.26, 37.00, 39.70, 44.32, 68.13, 69.84, 109.48 (d, J = 2.9 Hz), 110.35 (dd, J = 5.8 Hz, J = $15.3 \mathrm{~Hz}$ ), 114.98, 122.98 (d, $J=10.5 \mathrm{~Hz}), 123.48$ (t, $J=3.8 \mathrm{~Hz}), 127.44$ (d, J = 83.4 Hz), 128.56 (d, J = 2.9 Hz), 130.35 (d, $J=1.9 \mathrm{~Hz}), 132.33,137.00(\mathrm{~m}, J=4.8 \mathrm{~Hz}), 137.45,140.48,140.63,147.39,147.52$ (d, $J=$ $2.9 \mathrm{~Hz}), 147.63(\mathrm{~J}=2.9 \mathrm{~Hz}), 151.36$ (ddd, J = 4.8 Hz, J=10.5 Hz, J = 233.9 Hz), 159.47 
${ }^{19} \mathrm{~F} \mathrm{NMR}\left(\mathrm{CDCl}_{3}\right):-163.80(1 \mathrm{~F}, \mathrm{tt}, J=7.2 \mathrm{~Hz}, J=20.2 \mathrm{~Hz}, \operatorname{ArF}),-158.30(1 \mathrm{~F}, \mathrm{dd}, J=7.2 \mathrm{~Hz}, J=20.2$ $\mathrm{Hz}, \operatorname{Ar} F),-141.79(1 \mathrm{~F}, \mathrm{tt}, J=7.2 \mathrm{~Hz}, J=20.2 \mathrm{~Hz}, \operatorname{Ar} F),-134.41$ (1F, dd, $J=7.2 \mathrm{~Hz}, J=20.2 \mathrm{~Hz}, \operatorname{Ar} F$ )

FT-IR (cm-1): 721, 765, 800, 831, 896, 1008, 1039, 1080, 1103, 1141, 1215, 1249, 1296, 1315, 1471, $1506,1541,1558,1608,1749,2850,2918$

MS (ESI+): $729.3679\left(\mathrm{C}_{44} \mathrm{H}_{51} \mathrm{~F}_{5} \mathrm{NaO}_{2}, \mathrm{M}+\mathrm{Na}\right), 707.3845\left(100 \% \mathrm{C}_{44} \mathrm{H}_{52} \mathrm{~F}_{5} \mathrm{O}_{2}, \mathrm{M}+\mathrm{H}\right.$, calc. for $\left.\mathrm{C}_{44} \mathrm{H}_{52} \mathrm{~F}_{5} \mathrm{O}_{2} 707.3882\right)$

Assay (HPLC, C18, 230/265 nm): 99.2\%

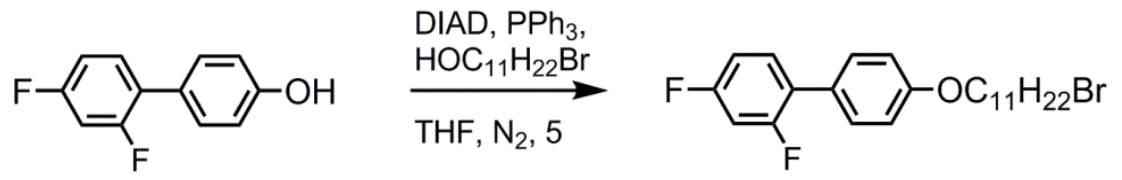

\section{2',4',-Difluoro-4-(11-bromoundecyloxy)biphenyl (i9)}

Quantities used: i6 (2 g, $9.708 \mathrm{mmol}), 11$-bromoundecanol (2.7 g, $10.68 \mathrm{mmol})$, triphenylphosphine (2.5 g, $9.708 \mathrm{mmol})$, DIAD (1.96 g, $1.91 \mathrm{ml}, 9.708 \mathrm{mmol})$, anhydrous THF (25 ml). The experimental procedure was as described for the synthesis of i3, with the title compound obtained via flash chromatography with 2:1 DCM/petroleum ether as the eluent, followed by recrystallisation from toluene, yielding the title compound as fine white crystals.

Yield: $3.3 \mathrm{~g}(77 \%)$

${ }^{1} \mathrm{H}$ NMR $\left(\mathrm{CDCl}_{3}\right): 1.27$ - $1.53\left(14 \mathrm{H}, \mathrm{m},-\mathrm{CH}_{2}-\left(\mathrm{CH}_{2}\right)_{7}-\mathrm{CH}_{2}-\right), 1.76-1.89\left(4 \mathrm{H}, \mathrm{m},-\mathrm{CH}_{2}-\mathrm{CH}_{2}-\left(\mathrm{CH}_{2}\right)_{7}-\mathrm{CH}_{2}-\right.$ $\left.\mathrm{CH}_{2}-\right), 3.41\left(2 \mathrm{H}, \mathrm{t}, J=6.7 \mathrm{~Hz}, \mathrm{Br}-\mathrm{CH}_{2}-\mathrm{CH}_{2-}\right), 3.98\left(2 \mathrm{H}, \mathrm{t}, \mathrm{J}=6.7 \mathrm{~Hz}, \mathrm{ArO}-\mathrm{CH}_{2}-\mathrm{CH}_{2}-\right), 6.85-6.94(2 \mathrm{H}$, $\mathrm{m}, \operatorname{ArH}), 6.96(2 \mathrm{H}, \mathrm{ddd}, J=2.1 \mathrm{~Hz}, J=2.8 \mathrm{~Hz}, J=8.9 \mathrm{~Hz}, \operatorname{ArH}), 7.36(\mathrm{dt}, J=6.4 \mathrm{~Hz}, J=8.9 \mathrm{~Hz}, \mathrm{ArH})$, $7.46(2 \mathrm{H}, \mathrm{dddd}, J=2.1 \mathrm{~Hz}, J=2.8 \mathrm{~Hz}, J=6.4 \mathrm{~Hz}, J=8.9 \mathrm{~Hz}, \operatorname{ArH})$

${ }_{19}^{19} \mathrm{NMR}\left(\mathrm{CDCl}_{3}\right)$ : -113.72 (1F, Quartet, $\left.J=8.0 \mathrm{~Hz}, \operatorname{ArF}\right),-112.34(1 \mathrm{~F}$, Quintet, $J=8.0 \mathrm{~Hz}, \operatorname{ArF})$

FT-IR (cm-1): 686, 721, 731, 765, 829, 862, 985, 1002, 1016, 1031, 1101, 1139, 1176, 1238, 1267, 1292, 1406, 1429, 1469, 1490, 1521, 1573, 1606, 2848, 2918 


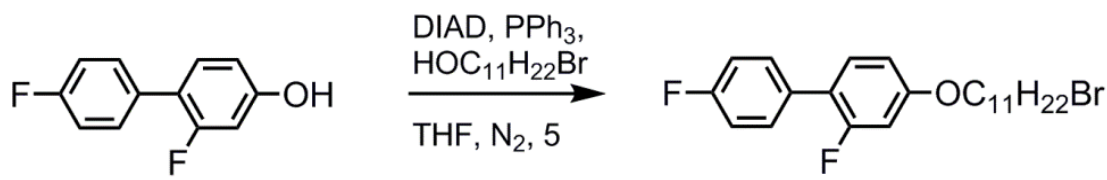

\section{2,4',-Difluoro-4-(11-bromoundecyloxy)biphenyl (i10)}

Quantities used: i7 (2 g, $9.708 \mathrm{mmol}), 11$-bromoundecanol $(2.7 \mathrm{~g}, 10.68 \mathrm{mmol})$, triphenylphosphine (2.5 g, $9.708 \mathrm{mmol})$, DIAD $(1.96 \mathrm{~g}, 1.91 \mathrm{ml}, 9.708 \mathrm{mmol})$, anhydrous THF $(25 \mathrm{ml})$. The experimental procedure was as described for the synthesis of $\mathbf{i} 3$, with the title compound obtained via flash chromatography with 2:1 DCM/petroleum ether as the eluent, followed by recrystallisation from toluene, yielding the title compound as fine white crystals.

Yield: $3.9 \mathrm{~g}(91 \%)$

${ }^{1} \mathrm{H}$ NMR $\left(\mathrm{CDCl}_{3}\right): 1.27-1.49\left(14 \mathrm{H}, \mathrm{m},-\mathrm{CH}_{2}-\left(\mathrm{CH}_{2}\right)_{7}-\mathrm{CH}_{2}-\right), 1.75-1.89\left(4 \mathrm{H}, \mathrm{m},-\mathrm{CH}_{2}-\mathrm{CH}_{2}-\left(\mathrm{CH}_{2}\right)_{7}-\mathrm{CH}_{2}-\right.$ $\left.\mathrm{CH}_{2}-\right), 3.41\left(2 \mathrm{H}, \mathrm{t}, \mathrm{J}=7.0 \mathrm{~Hz}, \mathrm{Br}-\mathrm{CH}_{2}-\mathrm{CH}_{2}-\right), 3.96\left(2 \mathrm{H}, \mathrm{t}, \mathrm{J}=7.0 \mathrm{~Hz}, \mathrm{ArO}_{-} \mathrm{CH}_{2}-\mathrm{CH}_{2}-\right), 6.68(1 \mathrm{H}, \mathrm{dd}, \mathrm{J}=$ $2.4 \mathrm{~Hz}, J=12.5 \mathrm{~Hz}, \operatorname{ArH}), 6.75(1 \mathrm{H}, \mathrm{ddd}, J=0.6 \mathrm{~Hz}, J=3.1 \mathrm{~Hz}, J=8.2 \mathrm{~Hz}, \operatorname{ArH}), 7.09$ (2H, dddd, $J=$ $2.1 \mathrm{~Hz}, J=3.1 \mathrm{~Hz}, J=8.5 \mathrm{~Hz}, J=8.9 \mathrm{~Hz}, \operatorname{ArH}), 7.28(1 \mathrm{H}, \mathrm{t}, J=8.9 \mathrm{~Hz}, \operatorname{ArH}), 7.46(2 \mathrm{H}, \mathrm{m}, \operatorname{ArH})$

19F NMR $\left(\mathrm{CDCl}_{3}\right):-115.89(1 \mathrm{~F}, \mathrm{t}, \mathrm{J}=10.3 \mathrm{~Hz}, \mathrm{ArF}),-115.43(1 \mathrm{~F}, \mathrm{~m}, \mathrm{ArF})$

FT-IR $\left(\mathrm{cm}^{-1}\right):$ 750, 800, 812, 840, 1006, 1037, 1093, 1124, 1157, 1230, 1284, 1394, 1469, 1496, 1571 , $1602,1624,1739,2848,2916$

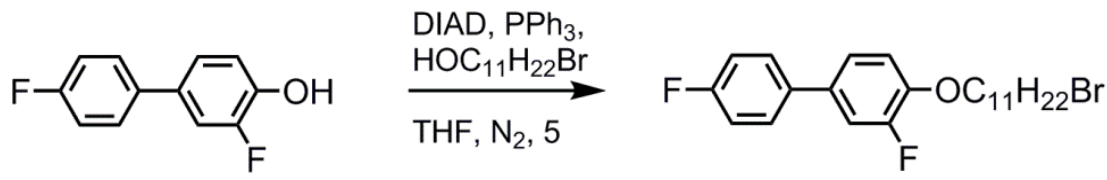

\section{3,4',-Difluoro-4-(11-bromoundecyloxy)biphenyl (i11)}

Quantities used: i7 (1 g, $4.854 \mathrm{mmol}), 11$-bromoundecanol (1.22 g, $4.854 \mathrm{mmol})$, triphenylphosphine (1.27 g, $4.854 \mathrm{mmol})$, DIAD (980 mg, $954 \mu \mathrm{l}, 4.854 \mathrm{mmol})$, anhydrous THF (10 ml). The experimental procedure was as described for the synthesis of $\mathbf{3} 3$, with the title compound obtained via flash chromatography with 2:1 DCM/petroleum ether as the eluent, followed by recrystallisation from toluene, yielding the title compound as fine white crystals.

Yield: $1.8 \mathrm{~g}(84 \%)$ 
${ }^{1} \mathrm{H}$ NMR $\left(\mathrm{CDCl}_{3}\right): 1.26-1.51\left(14 \mathrm{H}, \mathrm{m},-\mathrm{CH}_{2}-\left(\mathrm{CH}_{2}\right)_{7}-\mathrm{CH}_{2}-\right), 1.79-1.88\left(4 \mathrm{H}, \mathrm{m},-\mathrm{CH}_{2}-\mathrm{CH}_{2}-\left(\mathrm{CH}_{2}\right)_{7}-\mathrm{CH}_{2}-\right.$ $\left.\mathrm{CH}_{2}-\right), 3.39\left(2 \mathrm{H}, \mathrm{t}, \mathrm{J}=6.7 \mathrm{~Hz}, \mathrm{Br}-\mathrm{CH}_{2}-\mathrm{CH}_{2}-\right), 4.05\left(2 \mathrm{H}, \mathrm{t}, \mathrm{J}=6.3 \mathrm{~Hz}, \mathrm{ArO}-\mathrm{CH}_{2}-\mathrm{CH}_{2-}\right), 6.99(1 \mathrm{H}, \mathrm{t}, J=8.5$ $\mathrm{Hz}, \operatorname{ArH}), 7.09(1 \mathrm{H}, \mathrm{dddd}, J=2.1 \mathrm{~Hz}, J=3.1 \mathrm{~Hz}, J=8.5 \mathrm{~Hz}, J=8.9 \mathrm{~Hz}, \operatorname{ArH}), 7.19-7.23(1 \mathrm{H}, \mathrm{m}, \operatorname{ArH})$, $7.26(1 \mathrm{H}, \mathrm{dd}, J=2.4 \mathrm{~Hz}, J=12.2 \mathrm{~Hz}, \operatorname{ArH}), 7.46(2 \mathrm{H}, \mathrm{dddd}, J=2.1 \mathrm{~Hz}, J=3.1 \mathrm{~Hz}, J=5.5 \mathrm{~Hz}, J=8.9$ $\mathrm{Hz}, \mathrm{ArH})$

${ }^{19} \mathrm{~F} \mathrm{NMR}\left(\mathrm{CDCl}_{3}\right):-134.05(1 \mathrm{~F}, \mathrm{dd}, J=9.9 \mathrm{~Hz}, J=11.5 \mathrm{~Hz}, \operatorname{ArF}),-115.73(1 \mathrm{~F}, \mathrm{~m}, \mathrm{ArF})$

FT-IR (cm-1): 671, 721, 758, 804, 835, 883, 916, 962, 1010, 1047, 1103, 1132, 1166, 1240, 1278, 1296, $1309,1504,1537,1602,1737,2845,2916$

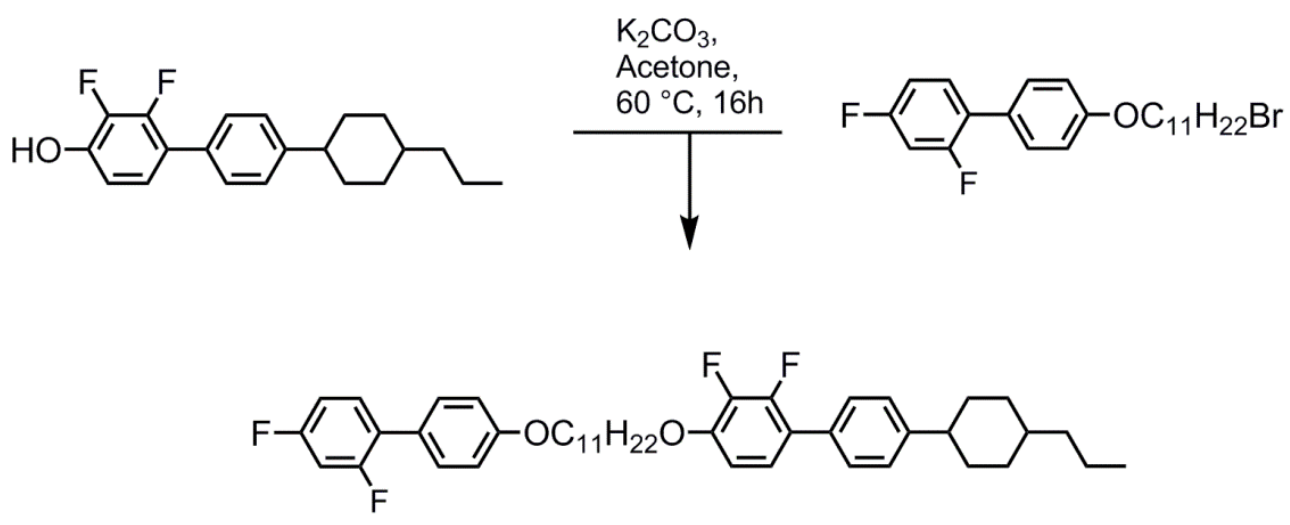

\section{4-((11-((2',4'-Difluoro-[1,1'-biphenyl]-4-yl)oxy)undecyl)oxy)-2,3-difluoro-4'-(4-propylcyclohexyl)- 1,1'-biphenyl (4)}

Quantities used: i9 (680 mg, $1.548 \mathrm{mmol}), 2,3-$ difluoro-4'-(4-propylcyclohexyl)-[1,1'-biphenyl]-4-ol (511 $\mathrm{mg}, 1.548 \mathrm{mmol})$, potassium carbonate $(427 \mathrm{mg}, 3.098 \mathrm{mmol})$, potassium iodide $(1 \mathrm{~g})$, acetone $(10 \mathrm{ml})$. The experimental procedure was as described for the synthesis of $i 3$, with the title compound obtained via flash chromatography with 1:1 DCM/hexane as the eluent, followed by recrystallisation of the title compound from ethanol, giving the target material as colourless plates.

Yield: $980 \mathrm{mg}(92 \%)$

${ }^{1} \mathrm{H}$ NMR $\left(\mathrm{CDCl}_{3}\right): 0.89\left(3 \mathrm{H}, \mathrm{t}, \mathrm{J}=7.0 \mathrm{~Hz}, \mathrm{CH}_{3}-\mathrm{CH}_{2}\right), 0.98-1.11\left(2 \mathrm{H}, \mathrm{m},-\mathrm{CH}_{2}-\mathrm{CH}_{2}-\mathrm{CH}_{3}\right), 1.16-1.53$ $\left(21 \mathrm{H}, \mathrm{m},-\mathrm{CH}_{2^{-}}+\mathrm{CyH}\right), 1.73-1.94\left(8 \mathrm{H}, \mathrm{m},-\mathrm{CH}_{2^{-}}+\mathrm{CyH}\right), 2.48(1 \mathrm{H}, \mathrm{tt}, J=3.2 \mathrm{~Hz}, J=11.9 \mathrm{~Hz}, \mathrm{CyH})$, $3.97\left(2 \mathrm{H}, \mathrm{t}, J=7.0 \mathrm{~Hz}, \operatorname{ArOCH}_{2^{-}}\right), 4.04\left(2 \mathrm{H}, \mathrm{t}, J=7.0 \mathrm{~Hz}, \operatorname{ArOCH}_{2^{-}}\right), 6.76(1 \mathrm{H}, \mathrm{dt}, J=2.3 \mathrm{~Hz}, J=8.7$ $\mathrm{Hz}, \mathrm{ArH}), 6.82-6.96(4 \mathrm{H}, \mathrm{m}, \mathrm{ArH}), 7.02-7.09(1 \mathrm{H}, \mathrm{dt}, J=2.3 \mathrm{~Hz}, J=8.7 \mathrm{~Hz}, \mathrm{ArH}), 7.23-7.28(2 \mathrm{H}$, m, $\mathrm{ArH}), 7.30-7.44$ (5H, m, ArH) 
${ }^{13} \mathrm{C} \mathrm{NMR}\left(\mathrm{CDCl}_{3}\right):$ 14.40, 20.01, 25.85, 26.01, 29.13, 29.23, 29.28, 29.34, 29.46, 29.48,29.50, 33.52, 34.26, 36.99, 39.70, 44.32, 68.02, 69.84, 104.25 (t, $J=25.4 \mathrm{~Hz}$ ), 109.48 (d, $J=2.9 \mathrm{~Hz}$ ), 111.41 (dd, $J=$ $3.8 \mathrm{~Hz}, J=20.1 \mathrm{~Hz}), 114.51,122.97(\mathrm{~d}, J=10.5 \mathrm{~Hz}), 123.47$ (t, J=4.8 Hz), 127.01, 128.57 (d, J = 2.9 Hz), 129.94 (d, $J=2.9 \mathrm{~Hz}), 131.03(\mathrm{~d}, J=4.8 \mathrm{~Hz}), 131.13(\mathrm{~d}, J=4.8 \mathrm{~Hz}), 132.48,141.71$ (dd, $J=14.4$ $\mathrm{Hz}, J=247.3 \mathrm{~Hz}), 147.38,147.52(\mathrm{~d}, J=1.9 \mathrm{~Hz}), 147.58(\mathrm{~d}, J=1.9 \mathrm{~Hz}), 147.63(\mathrm{~d}, J=1.9 \mathrm{~Hz})$, 158.82, $159.67(\mathrm{dd}, J=11.5 \mathrm{~Hz}, J=250.1 \mathrm{~Hz}), 160.59(\mathrm{~d}, J=11.5 \mathrm{~Hz})$

${ }^{19} \mathrm{~F} \mathrm{NMR}\left(\mathrm{CDCl}_{3}:-158.84(1 \mathrm{~F}, \mathrm{dd}, J=7.2 \mathrm{~Hz}, J=20.2 \mathrm{~Hz}, \operatorname{ArF}),-141.83(1 \mathrm{~F}, \mathrm{dd}, J=7.2 \mathrm{~Hz}, J=20.2\right.$ $\mathrm{Hz}, \operatorname{ArF}),-113.73(1 \mathrm{~F}$, quartet, $J=7.2 \mathrm{~Hz}, \operatorname{Ar} F),-112.38(1 \mathrm{~F}$, quintet, $J=7.2 \mathrm{~Hz}, \operatorname{Ar} F)$

FT-IR (cm-1): 692, 704, 721, 802, 839, 894, 962, 1074, 1122, 1161, 1205, 1228, 1294, 1365, 1471, $1494,1541,1625,1739,2848,2918,2970$

MS (ESI+): $727.3523\left(\mathrm{C}_{44} \mathrm{H}_{52} \mathrm{~F}_{4} \mathrm{KO}_{2}, \mathrm{M}+\mathrm{K}\right), 711.8797\left(100 \%, \mathrm{C}_{44} \mathrm{H}_{52} \mathrm{~F}_{4} \mathrm{NaO}_{2}, \mathrm{M}+\mathrm{Na}\right.$, calc. for $\left.\mathrm{C}_{44} \mathrm{H}_{52} \mathrm{~F}_{4} \mathrm{NaO}_{2} 711.8808\right)$

Assay (HPLC, C18, 230/265 nm): 99.5\%

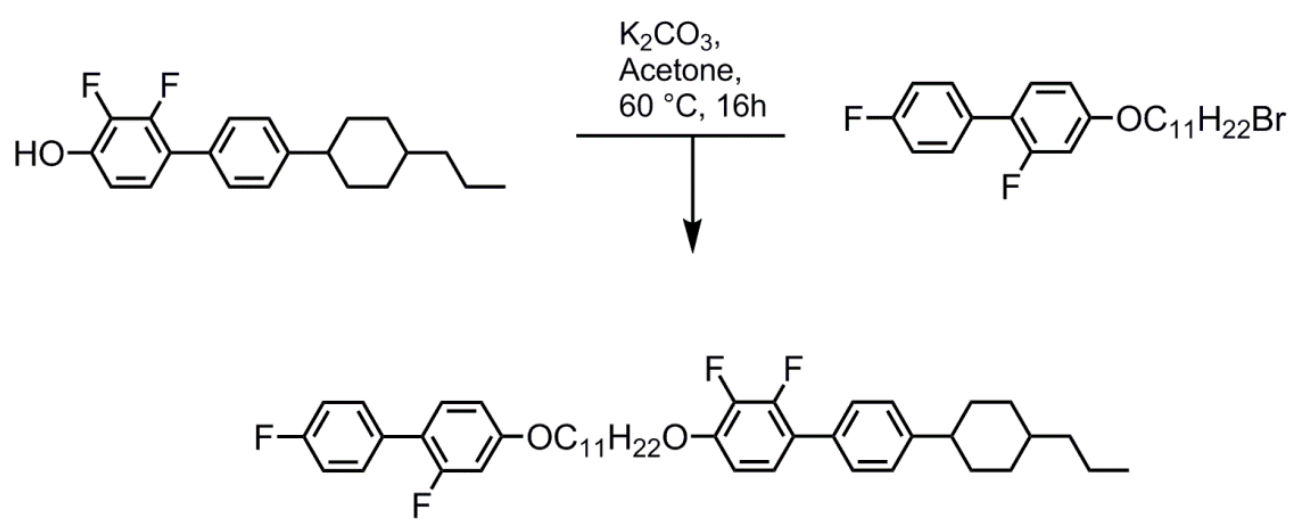

\section{4-((11-((2,4'-Difluoro-[1,1'-biphenyl]-4-yl)oxy)undecyl)oxy)-2,3-difluoro-4'-(4-propylcyclohexyl)-}

\section{1,1'-biphenyl (5)}

Quantities used: i10 (400 mg, 0.911 mmol), 2,3-difluoro-4'-(4-propylcyclohexyl)-[1,1'-biphenyl]-4-ol (300 g, $0.911 \mathrm{mmol})$, potassium carbonate $(251 \mathrm{mg}, 1.822 \mathrm{mmol})$, potassium iodide $(1 \mathrm{~g})$, acetone $(10 \mathrm{ml})$. The experimental procedure was as described for the synthesis of i3, with the title compound obtained via flash chromatography with 1:1 DCM/hexane as the eluent, followed by recrystallisation of the title compound from ethanol, giving the target material as colourless plates. 
Yield: $620 \mathrm{mg}(98 \%)$

${ }^{1} \mathrm{H}$ NMR $\left(\mathrm{CDCl}_{3}\right): 0.83\left(3 \mathrm{H}, \mathrm{t}, \mathrm{J}=7.3 \mathrm{~Hz}, \mathrm{CH}_{3}-\mathrm{CH}_{2}-\right), 0.94-1.47(22 \mathrm{H}, \mathrm{m}), 1.68-1.88(8 \mathrm{H}, \mathrm{m}), 2.43$ $(1 \mathrm{H}, \mathrm{tt}, J=3.1 \mathrm{~Hz}, J=11.9 \mathrm{~Hz}, \mathrm{Ar}-\mathrm{CyH}), 3.89\left(2 \mathrm{H}, \mathrm{t}, J=6.7 \mathrm{~Hz}, \mathrm{CH}_{2} \mathrm{OAr}\right), 3.99(2 \mathrm{H}, \mathrm{t}, J=6.7 \mathrm{~Hz}$, $\left.\mathrm{CH}_{2} \mathrm{OAr}\right), 6.62(1 \mathrm{H}, \mathrm{dd}, J=2.4 \mathrm{~Hz}, J=12.5 \mathrm{~Hz}, \mathrm{ArH}), 6.65-6.73(2 \mathrm{H}, \mathrm{m}, \mathrm{ArH}), 7.03(3 \mathrm{H}, \mathrm{m}, \mathrm{ArH}), 7.18$ $-7.23(3 \mathrm{H}, \mathrm{m}, \mathrm{ArH}), 7.33-7.41(4 \mathrm{H}, \mathrm{m}, \mathrm{ArH})$

${ }^{13} \mathrm{C}$ NMR $\left(\mathrm{CDCl}_{3}\right): 14.41,20.03,25.86,25.97,29.10,29.15,29.29,29.32,29.45,29.48,33.53,34.27$, 37.00, 39.71, 44.32, 68.42, 68.84, 102.24 (d, J = 26.9 Hz), 109.5 (d, J = 3.1 Hz), 110.84 (d, J = 3.1 Hz), $115.28(\mathrm{~d}, J=21.5 \mathrm{~Hz}), 120.12(\mathrm{~d}, J=14.6 \mathrm{~Hz}), 122.98(\mathrm{~d}, J=11.5 \mathrm{~Hz}), 123.44(\mathrm{t}, J=4.6 \mathrm{~Hz}), 127.03$, 128.58 (d, $J=3.1 \mathrm{~Hz}), 130.32$ (dd, $J=4.2 \mathrm{~Hz}, J=8.4 \mathrm{~Hz}$ ), 130.77 (d, $J=5.4 \mathrm{~Hz}$ ), 131.77, 132.35, 147.40, 147.55 (dd, J = 3.1 Hz, J = 8.4 Hz), 159.38 (d, J = 97.4 Hz), 160.29 (d, J = 106.6 Hz), 162.31 (d, $J=192.56 \mathrm{~Hz})$

19F NMR $\left(\mathrm{CDCl}_{3}\right):-158.84(1 \mathrm{~F}, \mathrm{dd}, J=8.0 \mathrm{~Hz}, J=19.5 \mathrm{~Hz}, \operatorname{ArF}),-141.83(1 \mathrm{~F}, \mathrm{dd}, J=8.0 \mathrm{~Hz}, J=19.5$ $\mathrm{Hz}, \operatorname{Ar} F),-115.90(1 \mathrm{~F}, \mathrm{t}, J=10.3 \mathrm{~Hz}, \operatorname{ArF}),-115.44(1 \mathrm{~F}, \mathrm{ddd}, \mathrm{J}=5.8 \mathrm{~Hz}, J=9.2 \mathrm{~Hz}, J=14.9 \mathrm{~Hz}, \operatorname{ArF})$

FT-IR (cm-1): 690, 719, 798, 835, 894, 968, 1014, 1049, 1078, 1105, 1132, 1217, 1228, 1313, 1365 , $1469,1506,1558,1739,2850,2918,2970$

MS (ESI+): $727.3521\left(\mathrm{C}_{44} \mathrm{H}_{52} \mathrm{~F}_{4} \mathrm{KO}_{2}, \mathrm{M}+\mathrm{K}\right), 711.8796\left(100 \%, \mathrm{C}_{44} \mathrm{H}_{52} \mathrm{~F}_{4} \mathrm{NaO}_{2}, \mathrm{M}+\mathrm{Na}\right.$, calc. for $\left.\mathrm{C}_{44} \mathrm{H}_{52} \mathrm{~F}_{4} \mathrm{NaO}_{2} 711.8808\right)$

Assay (HPLC, C18, 230/265 nm): 99.6\%
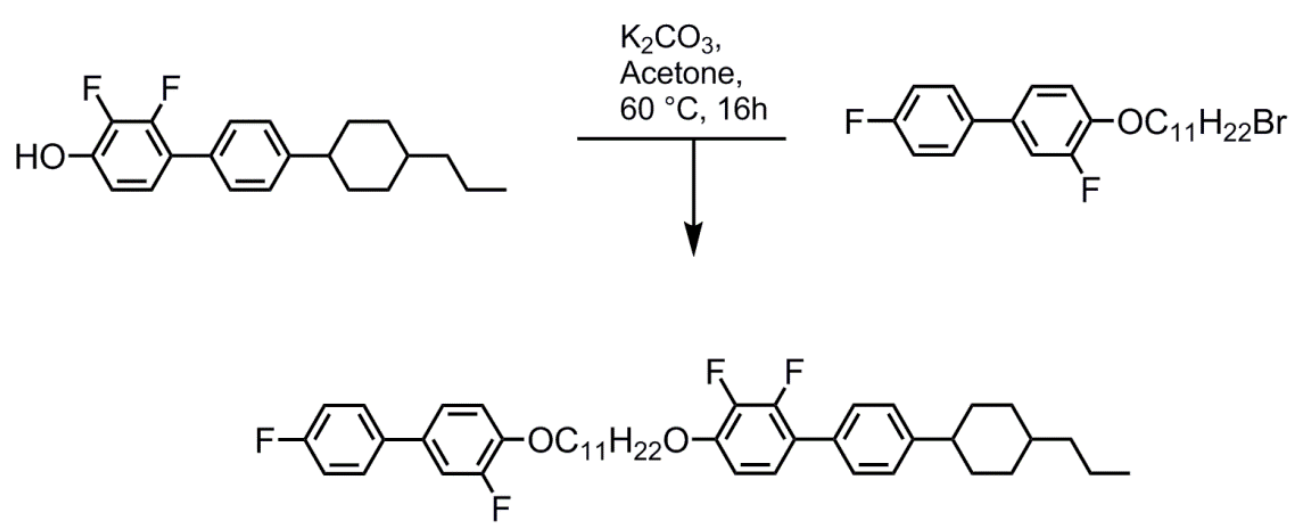


\section{4-((11-((3,4'-Difluoro-[1,1'-biphenyl]-4-yl)oxy)undecyl)oxy)-2,3-difluoro-4'-(4-propylcyclohexyl)-}

\section{1,1'-biphenyl (6)}

Quantities used: i11 (200 mg, 0.456 mmol), 2,3-difluoro-4'-(4-propylcyclohexyl)-[1,1'-biphenyl]-4-ol (150 $\mathrm{mg}, 0.456 \mathrm{mmol})$, potassium carbonate $(125 \mathrm{mg}, 0.911 \mathrm{mmol})$, potassium iodide $(1 \mathrm{~g})$, acetone $(10 \mathrm{ml})$. The experimental procedure was as described for the synthesis of i3, with the title compound obtained via flash chromatography with 1:1 DCM/hexane as the eluent, followed by recrystallisation of the title compound from ethanol, giving the target material as colourless plates.

Yield: $240 \mathrm{mg}(77 \%)$

${ }^{1} \mathrm{H} \mathrm{NMR}\left(\mathrm{CDCl}_{3}\right): 0.83\left(3 \mathrm{H}, \mathrm{t}, J=7.3 \mathrm{~Hz}, \mathrm{CH}_{3}-\mathrm{CH}_{2}-\right), 0.94-1.47(22 \mathrm{H}, \mathrm{m}), 1.68-1.88(8 \mathrm{H}, \mathrm{m}), 2.43$ $(1 \mathrm{H}, \mathrm{tt}, J=3.1 \mathrm{~Hz}, J=11.9 \mathrm{~Hz}, \mathrm{Ar}-\mathrm{CyH}), 3.89\left(2 \mathrm{H}, \mathrm{t}, J=6.7 \mathrm{~Hz}, \mathrm{CH}_{2} \mathrm{OAr}\right), 3.99(2 \mathrm{H}, \mathrm{t}, J=6.7 \mathrm{~Hz}$, $\left.\mathrm{CH}_{2} \mathrm{OAr}\right), 6.62(1 \mathrm{H}, \mathrm{dd}, J=2.4 \mathrm{~Hz}, J=12.5 \mathrm{~Hz}, \mathrm{ArH}), 6.65-6.73(2 \mathrm{H}, \mathrm{m}, \mathrm{ArH}), 7.03(3 \mathrm{H}, \mathrm{m}, \mathrm{ArH}), 7.18$ $-7.23(3 \mathrm{H}, \mathrm{m}, \mathrm{ArH}), 7.33-7.41(4 \mathrm{H}, \mathrm{m}, \mathrm{ArH})$

${ }^{13} \mathrm{C} \mathrm{NMR}\left(\mathrm{CDCl}_{3}\right):$ 14.40, 20.01, 25.84, 25.89, 29.13, 29.18, 29.28, 29.31, 29.43, 29.47, 33.52, 34.26, 36.99, 39.69, 44.31, 69.52, 69.82, 109.47 (d, J = 2.3 Hz), 114.69 (d, J = $19.2 \mathrm{~Hz}$ ), 115.01 (d, $J=2.3$ $\mathrm{Hz}), 115.65$ (d, $J=21.5 \mathrm{~Hz}), 112.43(\mathrm{~d}, J=3.1 \mathrm{~Hz}), 122.95$ (d, $J=10.7 \mathrm{~Hz}), 123.44$ (d, J = 3.8 Hz), 127.01, 128.19 (d, J = 7.7 Hz), 128.57 (d, J = 3.1 Hz), 132.34, 133.28 (d, J = 6.1 Hz), 135.89, 140.54 (d, $J=13.5 \mathrm{~Hz}$ ), 143.00 (d, J = 15.3 Hz), 146.51 (d, $J=10.7 \mathrm{~Hz}), 147.37,147.57$ (d, J = 8.4 Hz), 148.86 (dd, $J=11.5 \mathrm{~Hz}, J=250.9 \mathrm{~Hz}), 152.78$ (d, J = 245.5 Hz), 162.29 (d, J = 245.3 Hz)

${ }^{19} \mathrm{~F} \mathrm{NMR}\left(\mathrm{CDCl}_{3}\right):-158.82(1 \mathrm{~F}, \mathrm{dd}, J=6.9 \mathrm{~Hz}, J=19.5 \mathrm{~Hz}, \mathrm{ArF}),-141.81(1 \mathrm{~F}, \mathrm{dd}, J=8.0 \mathrm{~Hz}, J=19.5$ $\mathrm{Hz}, \operatorname{Ar} F),-134.04(1 \mathrm{~F}, \mathrm{dd}, J=9.2 \mathrm{~Hz}, J=11.5 \mathrm{~Hz}, \operatorname{Ar} F),-115.70(1 \mathrm{~F}, \mathrm{ddd}, J=4.6 \mathrm{~Hz}, J=8.0 \mathrm{~Hz}, J=$ 13.8 Hz, ArF)

FT-IR (cm-1): 692, 704, 721, 802, 839, 894, 993, 1029, 1074, 1122, 1161, 1205, 1228, 1292, 1371, $1471,1494,1541,1625,1739,2848,2920,2970$

MS (ESI+): $727.3519\left(\mathrm{C}_{44} \mathrm{H}_{52} \mathrm{~F}_{4} \mathrm{KO}_{2}, \mathrm{M}+\mathrm{K}\right), 711.8800\left(100 \%, \mathrm{C}_{44} \mathrm{H}_{52} \mathrm{~F}_{4} \mathrm{NaO}_{2}, \mathrm{M}+\mathrm{Na}\right.$, calc. for $\left.\mathrm{C}_{44} \mathrm{H}_{52} \mathrm{~F}_{4} \mathrm{NaO}_{2} 711.8808\right)$

Assay (HPLC, C18, 230/265 nm): 99.4\% 


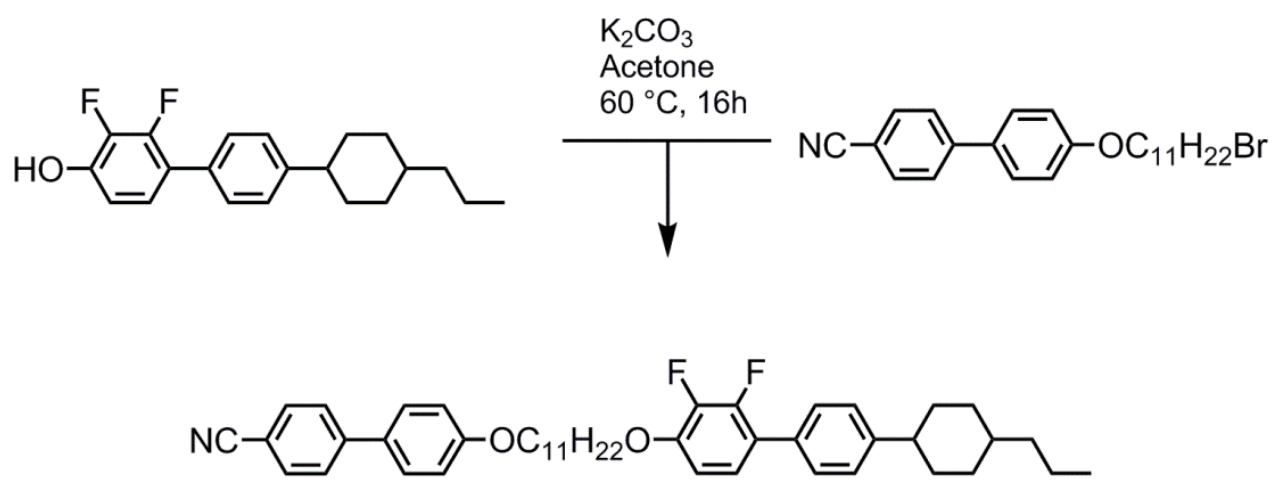

\section{4'-((11-((2,3-Difluoro-4'-(4-propylcyclohexyl)-[1,1'-biphenyl]-4-yl)oxy)undecyl)oxy)-[1,1'-biphenyl]- 4-carbonitrile (7)}

Quantities used: i15 (300 mg, $0.7 \mathrm{mmol}), 2,3$-difluoro-4'-(4-propylcyclohexyl)-[1,1'-biphenyl]-4-ol (243 $\mathrm{mg}, 0.735 \mathrm{mmmol}$ ), potassium carbonate (194 mg, $1.401 \mathrm{mmol}$ ), potassium iodide $(0.5 \mathrm{~g})$, acetone (02 $\mathrm{ml}$ ). The experimental procedure was as described for the synthesis of i3, with the title compound obtained via flash chromatography with 1:1 DCM/hexane as the eluent, followed by recrystallisation of the title compound from ethanol, giving the target material as colourless plates.

Yield: $270 \mathrm{mg}(57 \%)$

${ }^{1} \mathrm{H} \mathrm{NMR}\left(\mathrm{CDCl}_{3}\right): 0.83\left(3 \mathrm{H}, \mathrm{t}, \mathrm{J}=7.3 \mathrm{~Hz}, \mathrm{CH}_{3}-\mathrm{CH}_{2}-\right), 0.94-1.48(23 \mathrm{H}, \mathrm{m}), 1.69-1.89(8 \mathrm{H}, \mathrm{m}), 2.43$ $(1 \mathrm{H}, \mathrm{tt}, J=3.2 \mathrm{~Hz}, J=12.1 \mathrm{~Hz}, \mathrm{Ar}-\mathrm{CyH}), 3.93\left(2 \mathrm{H}, \mathrm{t}, J=7.0 \mathrm{~Hz}, \mathrm{CH}_{2} \mathrm{OAr}\right), 3.99(2 \mathrm{H}, \mathrm{t}, J=7.0 \mathrm{~Hz}$, $\left.\mathrm{CH}_{2} \mathrm{OAr}\right), 6.62(1 \mathrm{H}, \mathrm{td}, J=1.4 \mathrm{~Hz}, J=8.7 \mathrm{~Hz}, \mathrm{ArH}), 6.88-6.94(2 \mathrm{H}, \mathrm{m}, \mathrm{ArH}), 7.00(1 \mathrm{H}, \mathrm{td}, J=1.4 \mathrm{~Hz}$, $J=8.7 \mathrm{~Hz}, \mathrm{ArH}), 7.16-7.22(2 \mathrm{H}, \mathrm{m}, \mathrm{ArH}), 7.32-7.37(2 \mathrm{H}, \mathrm{m}, \mathrm{ArH}), 7.42-7.47(2 \mathrm{H}, \mathrm{m}, \mathrm{ArH}), 7.54-$ $7.58(2 \mathrm{H}, \mathrm{m}, \mathrm{ArH}), 7.59-7.63(2 \mathrm{H}, \mathrm{m}, \mathrm{ArH})$

${ }^{13} \mathrm{C}$ NMR $\left(\mathrm{CDCl}_{3}\right): 14.40,20.02,25.85,26.00,29.13,29.19,29.27,29.32,29.44,29.47,29.49,33.52$, $34.26,36.99,39.69,44.31,68.14,69.84,109.48(\mathrm{~d}, J=2.9 \mathrm{~Hz}), 109.99,115.06,119.11,122.98(\mathrm{~d}, J=$ $10.5 \mathrm{~Hz}), 123.48(\mathrm{t}, J=3.8 \mathrm{~Hz}), 127.03(\mathrm{~d}, J=1.9 \mathrm{~Hz}), 128.29,128.55(\mathrm{~d}, J=2.9 \mathrm{~Hz}), 131.21,132.30$, $132.53,147.40,146.33(\mathrm{~d}, J=214.7 \mathrm{~Hz}), 147.53,147.58,147.61,147.64,159.78$

19F NMR (CDCl $\left.)_{3}\right)-158.83(1 F, d d, J=7.2 \mathrm{~Hz}, J=20.2 \mathrm{~Hz}, \operatorname{ArF}),-141.81$ (1F, dd, $J=7.2 \mathrm{~Hz}, J=20.2$ $\mathrm{Hz}, \mathrm{ArF})$

FT-IR (cm-1): 661, 688, 723, 775, 798, 808, 821, 850, 893, 1012, 1037, 1078, 1105, 1217, 1296, 1311 , $1365,1494,1504,1604,1735,2222,2850,2970,3026$

MS (ESI+): $716.3671\left(\mathrm{C}_{45} \mathrm{H}_{53} \mathrm{~F}_{2} \mathrm{KNO}_{2}, \mathrm{M}+\mathrm{K}\right), 700.3933\left(100 \%, \mathrm{C}_{45} \mathrm{H}_{53} \mathrm{~F}_{2} \mathrm{NNaO}_{2}, \mathrm{M}+\mathrm{Na}\right.$, calc. for $\mathrm{C}_{45} \mathrm{H}_{53} \mathrm{~F}_{2} \mathrm{NNaO}_{2}$ 700.3937) 


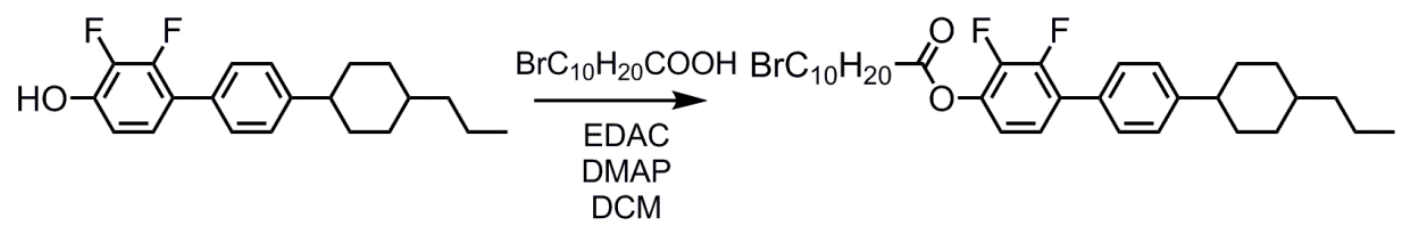

\section{2,3-Difluoro-4'-(4-propylcyclohexyl)-[1,1'-biphenyl]-4-yl 11-bromoundecanoate (i16)}

To a stirred solution of 2,3-difluoro-4'-(4-propylcyclohexyl)-[1,1'-biphenyl]-4-ol (500 mg, $1.515 \mathrm{mmol})$, 10-bromodecanoic acid (441 mg, $1.666 \mathrm{mmol}$ ) and EDAC (318 mg, $1.666 \mathrm{mmol})$, in anhydrous DCM $(10 \mathrm{ml})$ under an atmosphere of dry nitrogen was added DMAP $(50 \mathrm{mg})$ and the solution stirred for $1 \mathrm{~h}$, at which point TLC analysis showed complete consumption 2,3-difluoro-4'-(4-propylcyclohexyl)-[1,1'biphenyl]-4-ol. The solvent was removed in vacuo and the crude material subjected to flash chromatography with DCM as the eluent, followed by recrystallisation of the chromatographed material from ethanol, giving the title compound as colourless plates.

Yield: $720 \mathrm{mg}(82 \%)$

${ }^{1} \mathrm{H} \operatorname{NMR}\left(\mathrm{CDCl}_{3}\right): 0.89\left(3 \mathrm{H}, \mathrm{t}, \mathrm{J}=7.0 \mathrm{~Hz}, \mathrm{CH}_{3}-\mathrm{CH}_{2}\right), 0.99-1.11\left(2 \mathrm{H}, \mathrm{m}, \mathrm{CH}_{3}-\mathrm{CH}_{2}-\mathrm{CH}_{2}\right), 1.17-1.53$ $\left(19 \mathrm{H}, \mathrm{m},-\left(\mathrm{CH}_{2}\right)_{5}+\mathrm{CyH}_{9}\right), 1.72-1.95\left(8 \mathrm{H}, \mathrm{m},-\mathrm{CH}_{2}-\left(\mathrm{CH}_{2}\right)_{4}-\mathrm{CH}_{2}-\right), 2.50(1 \mathrm{H}, \mathrm{tt}, J=3.4 \mathrm{~Hz}, J=11.9 \mathrm{~Hz}$, Ar-CyH), $2.61\left(2 \mathrm{H}, \mathrm{t}, J=7.3 \mathrm{~Hz}, \mathrm{CH}_{2}-\mathrm{COOAr}\right), 3.39\left(2 \mathrm{H}, \mathrm{t}, J=7.3 \mathrm{~Hz}, \mathrm{CH}_{2}-\mathrm{Br}\right), 6.93$ (1H, ddd, $J=1.8$ $\mathrm{Hz}, J=7.0 \mathrm{~Hz}, J=8.9 \mathrm{~Hz}, \operatorname{ArH}), 7.15(1 \mathrm{H}, \mathrm{ddd}, J=2.1 \mathrm{~Hz}, J=7.6 \mathrm{~Hz}, J=8.5 \mathrm{~Hz}, \operatorname{ArH}), 7.28(2 \mathrm{H}, \mathrm{ddd}$, $J=1.5 \mathrm{~Hz}, J=2.4 \mathrm{~Hz}, J=7.9 \mathrm{~Hz}, \operatorname{ArH}), 7.42(2 \mathrm{H}, \mathrm{dddd}, J=1.5 \mathrm{~Hz}, J=1.8 \mathrm{~Hz}, J=2.4 \mathrm{~Hz}, J=7.9 \mathrm{~Hz}$, $\mathrm{ArH}$

${ }^{19} \mathrm{~F} \mathrm{NMR}\left(\mathrm{CDCl}_{3}\right):-150.55(1 \mathrm{~F}, \mathrm{dd}, J=4.3 \mathrm{~Hz}, J=20.2 \mathrm{~Hz}, \operatorname{ArF}),-140.40(1 \mathrm{~F}, \mathrm{dd}, J=7.2 \mathrm{~Hz}, J=20.2$ $\mathrm{Hz}, \mathrm{ArF})$

FT-IR (cm-1): 698, 727, 761, 792, 827, 891, 958, 1035, 1120, 1217, 1290, 1446, 1506, 1539, 1577 , $1610,1737,2854,2926,2970$ 
<smiles>Oc1ccc(-c2ccc(F)cc2)cc1</smiles>

\section{4'-Fluoro-[1,1'-biphenyl]-4-yl 11-bromoundecanoate (i18)}

Quantities used: 4-hydroxy-4'-fluorobiphenyl (1 g g, 5.319 mmol), 10-bromodecanoic acid (1.6 g, 5.851 $\mathrm{mmol})$, EDAC (1.2 g, $5.851 \mathrm{mmol})$, DMAP $(50 \mathrm{mg})$, DCM $(30 \mathrm{ml})$. The experimental procedure was as described for the synthesis of i16, with the title compound obtained via flash chromatography with 1:1 $D C M /$ hexane as the eluent, followed by recrystallisation of the title compound from ethanol, giving the target material as colourless plates.

Yield: $1.9 \mathrm{~g}(82 \%)$

${ }^{1} \mathrm{H}$ NMR $\left(\mathrm{CDCl}_{3}\right): 1.29-1.48\left(12 \mathrm{H}, \mathrm{m}, \mathrm{CH}_{2}-\left(\mathrm{CH}_{2}\right)_{6}-\mathrm{CH}_{2}-\right), 1.77\left(2 \mathrm{H}\right.$, Quintet, $J=7.6 \mathrm{~Hz}, \mathrm{CH}_{2}-\left(\mathrm{CH}_{2}\right)_{6}-$ $\left.\mathrm{CH}_{2}-\mathrm{CH}_{2-}\right), 1.86\left(2 \mathrm{H}\right.$, Quintet, $\left.J=7.6 \mathrm{~Hz}, \mathrm{CH}_{2}-\left(\mathrm{CH}_{2}\right)_{6}-\mathrm{CH}_{2}-\mathrm{CH}_{2-}\right), 2.58\left(2 \mathrm{H}, \mathrm{t}, J=7.6 \mathrm{~Hz}, \mathrm{CH}_{2-}\left(\mathrm{CH}_{2}\right)_{9-}\right.$ $\left.\mathrm{CH}_{2}-\mathrm{COOAr}\right), 3.41\left(2 \mathrm{H}, \mathrm{t}, \mathrm{J}=7.6 \mathrm{~Hz}, \operatorname{ArCOO}-\left(\mathrm{CH}_{2}\right)_{9}-\mathrm{CH}_{2}-\mathrm{Br}\right), 7.11(2 \mathrm{H}, \mathrm{ddd}, J=2.1 \mathrm{~Hz}, J=3.1 \mathrm{~Hz}, J=$ $8.9 \mathrm{~Hz}, \mathrm{ArH}), 7.13-7.17(2 \mathrm{H}, \mathrm{m}, \mathrm{ArH}), 7.49-7.55(4 \mathrm{H}, \mathrm{m}, \mathrm{ArH})$

19F NMR ( $\left.\mathrm{CDCl}_{3}\right):-116.73(1 \mathrm{~F}, \mathrm{tt}, J=5.3 \mathrm{~Hz}, J=8.7 \mathrm{~Hz}, \mathrm{ArF})$

FTIR: 719, 804, 827, 927, 1112, 1151, 1174, 1205, 1382, 1417, 1469, 1494, 1597, 1743, 2850, 2914 

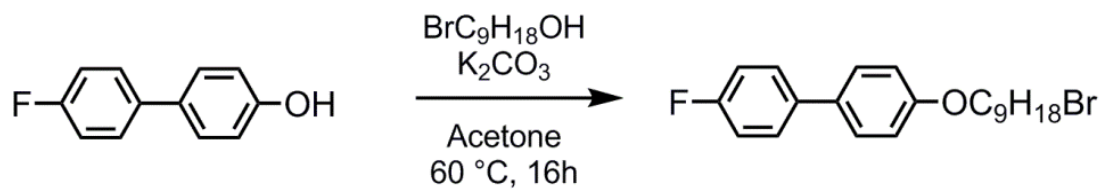

\section{4-((9-Bromononyl)oxy)-4'-fluorobiphenyl (i19)}

Quantities used: 4-hydroxy-4'-fluorobiphenyl (1.5 g, $7.98 \mathrm{mmol})$, 9-bromononanol (1.96 g, $8.77 \mathrm{mmol})$, triphenylphosphine ( $2.1 \mathrm{~g}, 7.98 \mathrm{mmol})$, DIAD (1.61 g, $1.57 \mathrm{ml}, 7.98 \mathrm{mmol})$, anhydrous THF (30 ml). The experimental procedure was as described for the synthesis of $\mathbf{i} 3$, with the title compound obtained via flash chromatography with 2:1 DCM/petroleum ether as the eluent, followed by recrystallisation from toluene, yielding the title compound as fine white crystals.

Yield: $2.8 \mathrm{~g}(89 \%)$

${ }^{1}$ H NMR $\left(\mathrm{CDCl}_{3}\right): 1.28-1.50\left(10 \mathrm{H}, \mathrm{m}, \mathrm{CH}_{2}-\left(\mathrm{CH}_{2}\right)_{5}-\mathrm{CH}_{2}-\right), 1.79\left(2 \mathrm{H}\right.$, Quintet, $J=6.7 \mathrm{~Hz}, \mathrm{CH}_{2}-\left(\mathrm{CH}_{2}\right)_{6^{-}}$ $\left.\mathrm{CH}_{2}-\mathrm{CH}_{2}-\right), 1.85\left(2 \mathrm{H}\right.$, Quintet, $\left.\mathrm{J}=6.7 \mathrm{~Hz}, \mathrm{CH}_{2}-\left(\mathrm{CH}_{2}\right)_{6}-\mathrm{CH}_{2}-\mathrm{CH}_{2}\right), 3.40\left(2 \mathrm{H}, \mathrm{t}, \mathrm{J}=6.7 \mathrm{~Hz}\right.$, ArO- $\left(\mathrm{CH}_{2}\right)_{8}-$ $\left.\mathrm{CH}_{2}-\mathrm{Br}\right), 3.98\left(2 \mathrm{H}, \mathrm{t}, J=6.7 \mathrm{~Hz}, \mathrm{Br}-\left(\mathrm{CH}_{2}\right) \mathrm{g}_{-}-\mathrm{CH}_{2}-\mathrm{OAr}\right), 6.94(2 \mathrm{H}, \mathrm{ddd}, J=2.1 \mathrm{~Hz}, J=2.8 \mathrm{~Hz}, J=8.9 \mathrm{~Hz}$, ArH), $7.08(2 \mathrm{H}$, dddd, $J=2.1 \mathrm{~Hz}, J=3.1 \mathrm{~Hz}, J=8.5 \mathrm{~Hz}, J=8.9 \mathrm{~Hz}, \mathrm{ArH}), 7.41-7.51(4 \mathrm{H}, \mathrm{m}, \mathrm{ArH})$ 19F NMR (CDCl $)$ : $-116.67(1 \mathrm{~F}, \mathrm{tt}, J=4.6 \mathrm{~Hz}, J=9.2 \mathrm{~Hz}, \mathrm{ArF})$

FT-IR (cm-1): 721, 754, 765, 808, 821, 1010, 1029, 1130, 1163, 1188, 1234, 1269, 1286, 1325, 1371 , $1394,1473,1498,1573,1602,1739,2850,2920$ 

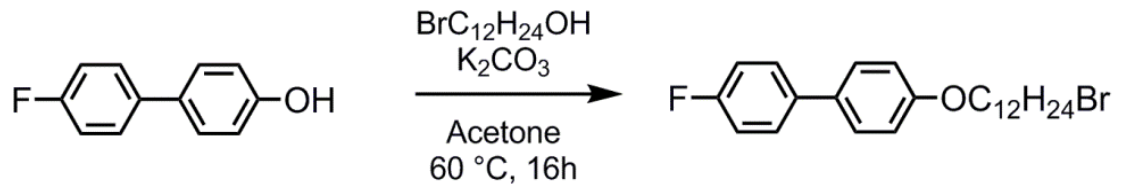

\section{4-((12-Bromododecyl)oxy)-4'-fluorobiphenyl (i20)}

Quantities used: 4-hydroxy-4'-fluorobiphenyl (1.5 g, $7.98 \mathrm{mmol})$, 12-bromododecanol (2.3 g, 8.77 mmol), triphenylphosphine $(2.1 \mathrm{~g}, 7.98 \mathrm{mmol})$, DIAD (1.61 g, $1.57 \mathrm{ml}, 7.98 \mathrm{mmol})$, anhydrous THF (40 $\mathrm{ml})$. The experimental procedure was as described for the synthesis of $\mathbf{3} 3$, with the title compound obtained via flash chromatography with $3: 1 \mathrm{DCM} /$ hexanes as the eluent, followed by recrystallisation from toluene/THF (approx. 20:1), yielding the title compound as fine white crystals.

Yield: $2.8 \mathrm{~g}(89 \%)$

${ }^{1} \mathrm{H}$ NMR $\left(\mathrm{CDCl}_{3}\right): 1.19\left(16 \mathrm{H}, \mathrm{m},-\mathrm{CH}_{2}-\left(\mathrm{CH}_{2}\right)_{8}-\mathrm{CH}_{2}-\right), 1.68-1.82\left(4 \mathrm{H}, \mathrm{m}, \mathrm{Br}-\mathrm{CH}_{2}-\mathrm{CH}_{2}-\left(\mathrm{CH}_{2}\right)_{8}-\mathrm{CH}_{2}-\right.$ $\left.\mathrm{CH}_{2} \mathrm{OAr}\right), 3.36\left(2 \mathrm{H}, \mathrm{t}, \mathrm{J}=6.9 \mathrm{~Hz}, \mathrm{Br}-\mathrm{CH}_{2}-\left(\mathrm{CH}_{2}\right){ }_{11} \mathrm{OAr}\right), 3.92\left(2 \mathrm{H}, \mathrm{t}, \mathrm{J}=6.9 \mathrm{~Hz}, \mathrm{ArO}-\mathrm{CH}_{2}-\left(\mathrm{CH}_{2}\right){ }_{11} \mathrm{Br}\right), 6.88$ $(2 \mathrm{H}, \mathrm{ddd}, J=1.8 \mathrm{~Hz}, J=3.2 \mathrm{~Hz}, J=8.7 \mathrm{~Hz}, \mathrm{ArH}), 7.02(2 \mathrm{H}, \mathrm{dddd}, J=1.8 \mathrm{~Hz}, J=3.2 \mathrm{~Hz}, J=7.1 \mathrm{~Hz}, J$ $=8.7 \mathrm{~Hz}, \mathrm{ArH}), 7.35-7.44(4 \mathrm{H}, \mathrm{m}, \mathrm{ArH})$

19F NMR (CDCl 3$):-116.73(1 \mathrm{~F}, \mathrm{~m}, \mathrm{ArF})$

FT-IR (cm-1): 719, 729, 808, 823, 977, 1031, 1051, 1163, 1209, 1230, 1288, 1365, 1462, 1473, 1498, $1573,1602,1737,2848,2918,2970$ 


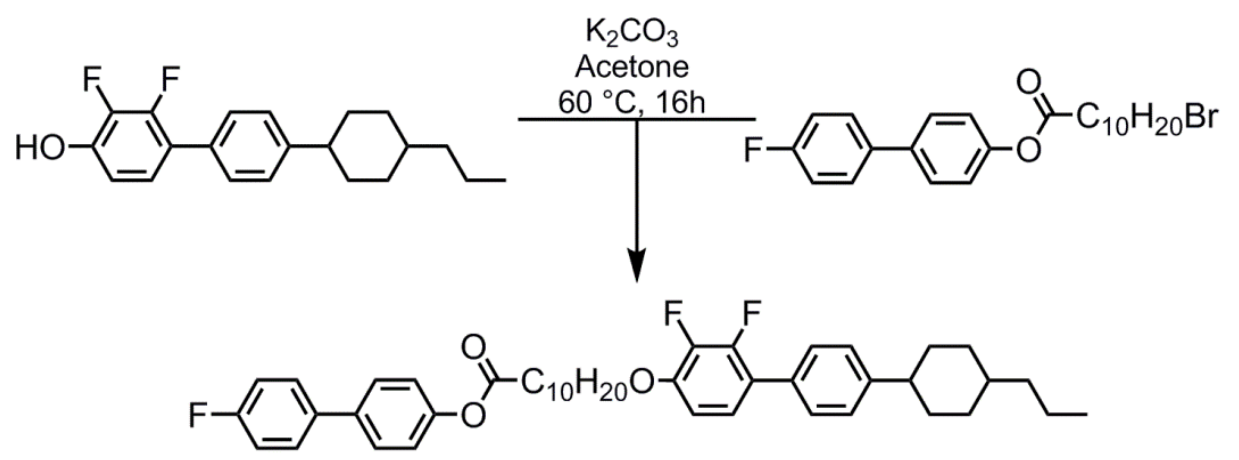

4'-Fluoro-[1,1'-biphenyl]-4-yl

11-((2,3-difluoro-4'-(4-propylcyclohexy))-[1,1'-biphenyl]-4yl)oxy)undecanoate (8)

Quantities used: 2,3-difluoro-4'-(4-propylcyclohexyl)-[1,1'-biphenyl]-4-ol (417 mg, $1.26 \mathrm{mmol}$ ), i18 (500 $\mathrm{mg}, 1.149 \mathrm{mmol}$ ), potassium carbonate $(348 \mathrm{mg}, 2.53 \mathrm{mmol})$, potassium iodide $(500 \mathrm{mg})$, acetone (25 $\mathrm{ml})$. The experimental procedure was as described for the synthesis of $\mathbf{i} 3$, with the title compound obtained via flash chromatography with 1:1 DCM/hexane as the eluent, followed by recrystallisation of the title compound from ethanol, giving the target material as colourless plates.

Yield: $510 \mathrm{mg}(65 \%)$

${ }^{1} \mathrm{H} \mathrm{NMR}\left(\mathrm{CDCl}_{3}\right): 0.89\left(3 \mathrm{H}, \mathrm{t}, \mathrm{J}=6.7,-\mathrm{CH}_{2}-\mathrm{CH}_{3}\right), 0.99-1.12\left(2 \mathrm{H}, \mathrm{m}, \mathrm{CH}_{2}-\mathrm{CH}_{2}-\mathrm{CH}_{3}\right), 1.17-1.53(19 \mathrm{H}$, m, $\left.\mathrm{CH}_{2}+\mathrm{CyH}\right), 1.71-1.95\left(8 \mathrm{H}, \mathrm{m}, \mathrm{CH}_{2}\right), 2.49(1 \mathrm{H}, \mathrm{tt}, J=3.2 \mathrm{~Hz}, J=11.9 \mathrm{~Hz}, \mathrm{CyH}), 2.57(2 \mathrm{H}, \mathrm{t}, J=$ $\left.7.3 \mathrm{~Hz}, \operatorname{ArOOC}-\mathrm{CH}_{2}-\mathrm{CH}_{2}\right), 4.05\left(2 \mathrm{H}, \mathrm{t}, J=7.3 \mathrm{~Hz}, \mathrm{ArO}-\mathrm{CH}_{2}-\mathrm{CH}_{2}\right), 6.76(1 \mathrm{H}, \mathrm{dt}, J=1.8 \mathrm{~Hz}, J=9.2 \mathrm{~Hz}$, ArH), $7.03-7.16(5 \mathrm{H}, \mathrm{m}, \mathrm{ArH}), 7.24-7.28(2 \mathrm{H}, \mathrm{m}, \mathrm{ArH}), 7.38-7.44(2 \mathrm{H}, \mathrm{m}, \mathrm{ArH}), 7.46-7.54(4 \mathrm{H}, \mathrm{m}$, $\mathrm{ArH})$

${ }^{13} \mathrm{C} \mathrm{NMR}\left(\mathrm{CDCl}_{3}\right): 14.40,20.02,24.92,25.75,29.07,29.13,29.19,29.26,29.33,29.42,33.53,34.26$, 34.39, 36.99, 39.70, 44.32, 69.83, $109.48(\mathrm{~d}, J=2.9 \mathrm{~Hz}), 115.63(\mathrm{~d}, J=21.1 \mathrm{~Hz}), 121.83,121.91$, $122.98(\mathrm{~d}, J=11.5 \mathrm{~Hz}), 123.48(\mathrm{~d}, J=3.8 \mathrm{~Hz}), 127.50(\mathrm{D}, J=96.8 \mathrm{~Hz}), 128.59,128.62(\mathrm{~d}, J=11.5$ $\mathrm{Hz}), 132.34,136.50$ (d, $J=2.9 \mathrm{~Hz}), 137.87,141.86$ (dd, $J=15.3 \mathrm{~Hz}, J=246.3 \mathrm{~Hz}), 147.38,147.52$ (d, $J=2.9 \mathrm{~Hz}), 147.59(\mathrm{t}, J=2.9 \mathrm{~Hz}), 150.13,162.44(\mathrm{~d}, J=246.3 \mathrm{~Hz}), 172.35$

19F NMR ( $\mathrm{CDCl}_{3}$ ): -158.87 (1F, ddd, $J=2.3 \mathrm{~Hz}, J=6.9 \mathrm{~Hz}, J=18.4 \mathrm{~Hz}, \operatorname{ArF}$ ), -141.84 (1F, dd, $J=6.9$ $\mathrm{Hz}, J=18.4 \mathrm{~Hz}, \operatorname{ArF}),-115.56(1 \mathrm{~F}, \mathrm{tt}, J=4.6 \mathrm{~Hz}, J=9.2 \mathrm{~Hz}, \operatorname{Ar} F)$

FT-IR (cm-1): 671, 690, 719, 738, 802, 823, 894, 921, 1006, 1076, 1103, 1139, 1213, 1298, 1313, 1471, $1749,2850,2916$

MS (ESI+): $723.3386\left(\mathrm{C}_{44} \mathrm{H}_{51} \mathrm{~F}_{3} \mathrm{KO}_{3}, \mathrm{M}+\mathrm{K}\right), 707.3652\left(100 \%, \mathrm{C}_{44} \mathrm{H}_{51} \mathrm{~F}_{3} \mathrm{NaO}_{3}, \mathrm{M}+\mathrm{Na}\right.$, calc. for $\left.\mathrm{C}_{44} \mathrm{H}_{51} \mathrm{~F}_{3} \mathrm{NaO}_{3} 707.3683\right)$ 


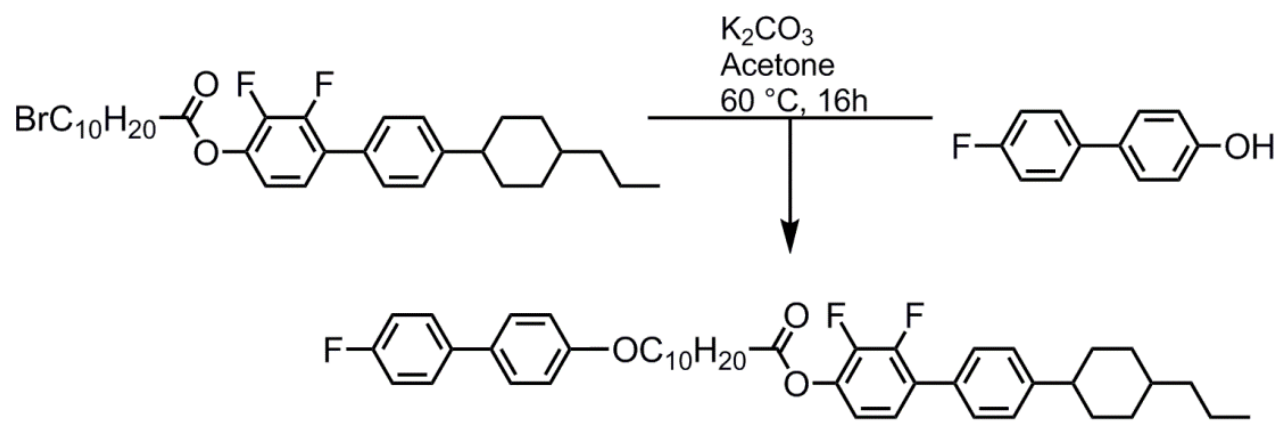

\section{2,3-Difluoro-4'-(4-propylcyclohexyl)-[1,1'-biphenyl]-4-yl}

11-((4'-fluoro-[1,1'-biphenyl]-4-

\section{yl)oxy)undecanoate (9)}

Quantities used: i16 (500 mg, $0.866 \mathrm{mmol}$ ), 4-hydroxy-4'-fluorobiphenyl (195 mg, 1.039 mmol), potassium carbonate $(358 \mathrm{mg}, 2.60 \mathrm{mmol})$, potassium iodide $(1 \mathrm{~g})$, acetone $(25 \mathrm{ml})$. The experimental procedure was as described for the synthesis of $\mathbf{3} 3$, with the title compound obtained via flash chromatography with $1: 1 \mathrm{DCM} /$ hexane as the eluent, followed by recrystallisation of the title compound from ethanol, giving the target material as colourless plates.

Yield: $560 \mathrm{mg}(95 \%)$

${ }^{1} \mathrm{H} \mathrm{NMR}\left(\mathrm{CDCl}_{3}\right): 0.89\left(3 \mathrm{H}, \mathrm{t}, \mathrm{J}=7.0 \mathrm{~Hz},-\mathrm{CH}_{2}-\mathrm{CH}_{3}\right), 0.98-1.12\left(2 \mathrm{H}, \mathrm{m}, \mathrm{CH}_{2}-\mathrm{CH}_{2}-\mathrm{CH}_{3}\right), 1.16-1.54$ $\left(19 \mathrm{H}, \mathrm{m}, \mathrm{CH}_{2}+\mathrm{CyH}\right), 1.70-1.96\left(8 \mathrm{H}, \mathrm{m}, \mathrm{CH}_{2}\right), 2.49(1 \mathrm{H}, \mathrm{tt}, \mathrm{J}=3.2 \mathrm{~Hz}, \mathrm{~J}=11.9 \mathrm{~Hz}, \mathrm{CyH}), 2.57(2 \mathrm{H}, \mathrm{t}$, $\left.J=7.3 \mathrm{~Hz}, \mathrm{ArOOC}-\mathrm{CH}_{2}-\mathrm{CH}_{2}\right), 4.05\left(2 \mathrm{H}, \mathrm{t}, \mathrm{J}=7.3 \mathrm{~Hz}, \mathrm{ArO}-\mathrm{CH}_{2}-\mathrm{CH}_{2}\right), 6.76(1 \mathrm{H}, \mathrm{m}, \mathrm{ArH}), 7.02-7.16$ $(5 \mathrm{H}, \mathrm{m}, \mathrm{ArH}), 7.23-7.29(2 \mathrm{H}, \mathrm{m}, \mathrm{ArH}), 7.38-7.45(2 \mathrm{H}, \mathrm{m}, \mathrm{ArH}), 7.46-7.54(4 \mathrm{H}, \mathrm{m}, \mathrm{ArH})$

${ }^{13} \mathrm{C} \mathrm{NMR}\left(\mathrm{CDCl}_{3}\right):$ 14.39, 20.01, 24.91, 25.84, 29.06, 29.13, 29.19, 29.26, 29.31, 29.41, 33.52, 34.26, 34.38, 36.99, 39.69, 44.31, 69.82, 109.48 (d, J = 2.9 Hz), 115.62 (d, J = 22.0 Hz), 121.90, 122.98 (d, J $=11.5 \mathrm{~Hz}), 123.45$ (t, J = 4.8 Hz), 127.50 (d, J = $97.8 \mathrm{~Hz}) 128.59,128.61$ (d, J = $11.5 \mathrm{~Hz}), 132.33$, 136.46 (d, $J=3.8 \mathrm{~Hz}$ ), 137.87, 140.62, 143.00 (d, $J=15.3 \mathrm{~Hz}$ ), 147.38, 147.57 (d, J = 3.8 Hz), 147.61 (d, $J=3.8 \mathrm{~Hz}), 150.13,162.43(\mathrm{~d}, J=247.3 \mathrm{~Hz}), 172.35$

19F NMR $\left(\mathrm{CDCl}_{3}\right):-158.82(\mathrm{dd}, J=5.8 \mathrm{~Hz}, J=18.8 \mathrm{~Hz}, \operatorname{ArF}),-141.82(\mathrm{dd}, J=5.8 \mathrm{~Hz}, J=18.8 \mathrm{~Hz}, \operatorname{Ar} F)$, -115.60 - -155.47 (m, ArF)

FT-IR (cm-1): 671, 690, 719, 740, 804, 823, 894, 921, 1006, 1076, 1103, 1145, 1217, 1298, 1315, 1371, 1471, 1494, 1558, 1635, 17439, 2850, 2918, 2970 
MS (ESI+): $723.3367\left(\mathrm{C}_{44} \mathrm{H}_{51} \mathrm{~F}_{3} \mathrm{KO}_{3}, \mathrm{M}+\mathrm{K}\right), 707.3666\left(100 \%, \mathrm{C}_{44} \mathrm{H}_{51} \mathrm{~F}_{3} \mathrm{NaO}_{3}, \mathrm{M}+\mathrm{Na}\right.$, calc. for $\mathrm{C}_{44} \mathrm{H}_{51} \mathrm{~F}_{3} \mathrm{NaO}_{3} 707.3683$ )

Assay (HPLC, C18, 230/265 nm): 99.6\%

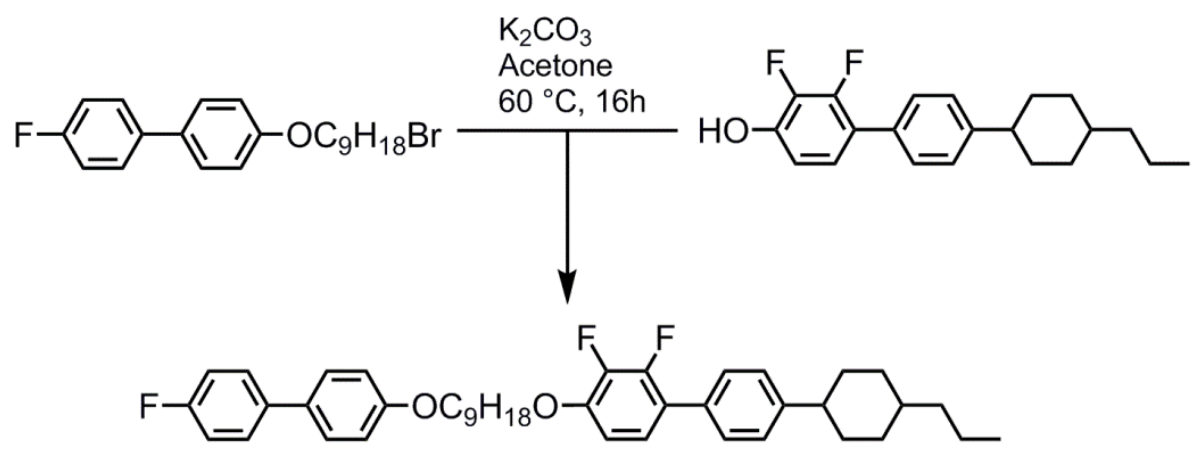

\section{2,3-Difluoro-4-((9-((4'-fluoro-[1,1'-biphenyl]-4-yl)oxy)nonyl)oxy)-4'-(4-propylcyclohexyl)-1,1'- biphenyl (10)}

Quantities used: 2,3-difluoro-4'-(4-propylcyclohexyl)-[1,1'-biphenyl]-4-ol (277 mg, 0.84 mmol), i19 (300 $\mathrm{mg}, 0.76 \mathrm{mmol})$, potassium carbonate $(210 \mathrm{mg}, 1.53 \mathrm{mmol})$, potassium iodide $(250 \mathrm{mg})$, acetone (10 $\mathrm{ml})$. The experimental procedure was as described for the synthesis of $\mathbf{3} 3$, with the title compound obtained via flash chromatography with 1:1 DCM/hexane as the eluent, followed by recrystallisation of the title compound from ethanol, giving the target material as colourless plates.

Yield: $400 \mathrm{mg}(82 \%)$

${ }^{1} \mathrm{H} \operatorname{NMR}\left(\mathrm{CDCl}_{3}\right): 0.86\left(3 \mathrm{H}, \mathrm{t}, \mathrm{J}=6.6 \mathrm{~Hz}, \mathrm{CH}_{3}-\mathrm{CH}_{2}\right), 0.95-1.08\left(2 \mathrm{H}, \mathrm{m}, \mathrm{CH}_{3}-\mathrm{CH}_{2}-\mathrm{CH}_{2}\right), 1.16-1.49$ $\left(17 \mathrm{H}, \mathrm{m}, \mathrm{CH}_{2}+\mathrm{CyH}\right), 1.71-1.93\left(8 \mathrm{H}, \mathrm{m}, \mathrm{CH}_{2}+\mathrm{CyH}\right), 2.45(1 \mathrm{H} \mathrm{tt}, \mathrm{J}=3.4 \mathrm{~Hz}, \mathrm{~J}=11.8 \mathrm{~Hz}, \mathrm{CyH}), 3.94$ $\left(2 \mathrm{H}, \mathrm{t}, \mathrm{J}=6.9 \mathrm{~Hz}, \mathrm{ArOCH}_{2}\right), 4.01\left(2 \mathrm{H}, \mathrm{t}, \mathrm{J}=6.9 \mathrm{~Hz}, \mathrm{ArOCH}_{2}\right), 6.72(1 \mathrm{H}, \mathrm{dt}, J=1.4 \mathrm{~Hz}, J=8.7 \mathrm{~Hz}, \mathrm{ArH})$, $6.90(2 \mathrm{H}, \mathrm{ddd}, J=1.8 \mathrm{~Hz}, J=2.8 \mathrm{~Hz}, J=8.7 \mathrm{~Hz}, \mathrm{ArH}), 6.99-7.07(3 \mathrm{H}, \mathrm{m}, \operatorname{ArH}), 7.19-7.24(2 \mathrm{H}, \mathrm{m}$, $\mathrm{ArH}) 7.35-7.47(6 \mathrm{H}, \mathrm{m}, \mathrm{ArH})$

${ }^{13} \mathrm{C}$ NMR $\left(\mathrm{CDCl}_{3}\right):$ 14.40, 20.02, 25.84, 26.00, 29.12, 29.21, 29.24, 29.26, 29.41, 33.53, 34.26, 37.00, 39.70, 44.32, 68.03, 69.81, 109.49 (d, $J=2.9 \mathrm{~Hz}), 114.78,115.48$ (d, $J=22.0 \mathrm{~Hz}$ ), 122.99 (d, J = 11.5 $\mathrm{Hz}), 123.46$ (t, J = 3.8 Hz), 127.49 (d, J = 92.9 Hz), 128.14 (d, J = 7.7 Hz), 128.59 (d, J = 2.9 Hz), 132.33, 132.56, 136.99 (d, J = 2.9 Hz), 141.86 (dd, J = $15.3 \mathrm{~Hz}, J=247.3 \mathrm{~Hz}$ ), 147.38, 147.51 (d, J = $3.8 \mathrm{~Hz}), 147.61$ (t, J = 3.8 Hz), $150.06(\mathrm{~d}, \mathrm{~J}=10.5 \mathrm{~Hz}), 158.65,162.02(\mathrm{~d}, \mathrm{~J}=245.4 \mathrm{~Hz})$ 
19F NMR $\left(\mathrm{CDCl}_{3}\right):-158.80(1 \mathrm{~F}, \mathrm{dd}, J=7.2 \mathrm{~Hz}, J=18.8 \mathrm{~Hz}, \operatorname{ArF}),-141.79(1 \mathrm{~F}, \mathrm{dd}, J=7.2 \mathrm{~Hz}, J=20.2$ $\mathrm{Hz}, \operatorname{ArF}),-116.67(1 \mathrm{~F}, \mathrm{~m}, \mathrm{ArF})$

FT-IR (cm-1): 688, 727, 775, 798, 821, 893, 1076, 1101, 1159, 1217, 1269, 1292, 1365, 1471, 1496, $1739,2850,2970$

MS (ESI+): $665.3552\left(100 \%, \mathrm{C}_{42} \mathrm{H}_{49} \mathrm{~F}_{3} \mathrm{NaO}_{2}, \mathrm{M}+\mathrm{Na}\right.$, calc. for $\left.\mathrm{C}_{42} \mathrm{H}_{49} \mathrm{~F}_{3} \mathrm{NaO}_{2} 665.3577\right)$

Assay (HPLC, C18, 230/265 nm): 99.2\%

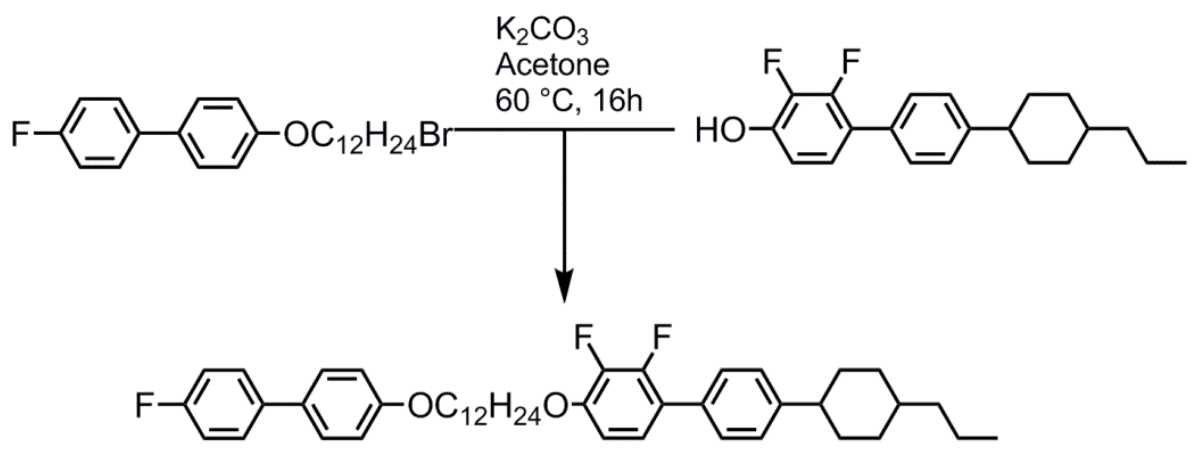

\section{2,3-Difluoro-4-((12-((4'-fluoro-[1,1'-biphenyl]-4-yl)oxy)dodecyl)oxy)-4'-(4-propylcyclohexyl)-1,1'- biphenyl (11)}

Quantities used: 2,3-difluoro-4'-(4-propylcyclohexyl)-[1,1'-biphenyl]-4-ol (277 mg, 0.84 mmol), i20 (300 $\mathrm{mg}, 0.72 \mathrm{mmol})$, potassium carbonate $(210 \mathrm{mg}, 1.53 \mathrm{mmol})$, potassium iodide $(250 \mathrm{mg})$, acetone (10 $\mathrm{ml}$ ). The experimental procedure was as described for the synthesis of $\mathbf{i} 3$, with the title compound obtained via flash chromatography with 1:1 DCM/hexane as the eluent, followed by recrystallisation of the title compound from ethanol giving the title compound as a pale yellow amorphous solid (300 mg). This material was found to be of insufficient purity (> $80 \%$ by HPLC, C18 column $100 \% \mathrm{H}_{3} \mathrm{CCN}$ ) and so a second recrystallisation from ethanol was undertaken, affording the title compound as a colourless solid.

Yield: $190 \mathrm{mg}(39 \%)$

${ }^{1} \mathrm{H} \mathrm{NMR}\left(\mathrm{CDCl}_{3}+\right.$ Acetone-D6): $0.89(\mathrm{t}, \mathrm{J}=7.2 \mathrm{~Hz}, 3 \mathrm{H}), 1.06(\mathrm{t}, \mathrm{J}=11.3 \mathrm{~Hz}, 2 \mathrm{H}), 1.53-1.16(\mathrm{~m}, 25 \mathrm{H})$, $1.95-1.74(\mathrm{~m}, 8 \mathrm{H}), 2.49(\mathrm{tt}, \mathrm{J}=12.3,3.1 \mathrm{~Hz}, 1 \mathrm{H}), 3.98(\mathrm{t}, \mathrm{J}=6.6 \mathrm{~Hz}, 2 \mathrm{H}), 4.05(\mathrm{t}, \mathrm{J}=6.6 \mathrm{~Hz}, 2 \mathrm{H}), 6.80$ - $6.71(\mathrm{~m}, 1 \mathrm{H}), 7.00-6.91(\mathrm{~m}, 2 \mathrm{H}), 7.14-7.00(\mathrm{~m}, 3 \mathrm{H}), 7.26(\mathrm{~d}, \mathrm{~J}=9.4 \mathrm{~Hz}, 4 \mathrm{H}), 7.44-7.38(\mathrm{~m}, 3 \mathrm{H})$, 7.47 (ddd, J = 10.3, 5.1, $1.9 \mathrm{~Hz}, 3 \mathrm{H}$ ). 


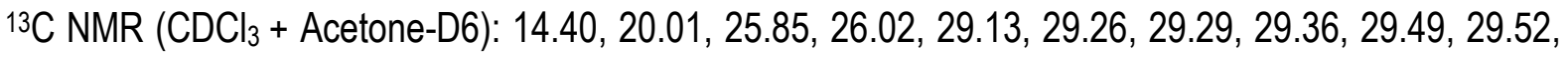
33.52, 34.25, 36.93, 39.69, 44.32, 68.07, 69.83, 109.46 (d, J = 2.9 Hz), 114.77, 115.47 (d, J = 21.1 Hz), 122.95 (d, J = 10.5 Hz), 123.43 (d, J = 3.8 Hz), 127.47 (d, $J=93.0 \mathrm{~Hz}), 128.14$ (d, J = 7.7 Hz), 128.56 (d, $J=2.9 \mathrm{~Hz}$ ), 132.33, 132.53, 136.99 (d, J = 2.9 Hz), 141.84 (dd, J=15.3 Hz, J = 245.4 Hz), 147.37, 147.49 (d, J = 2.3 Hz), 147.54 (t, J = 2.3 Hz), 150.05 (d, J = 11.5 Hz), 158.65, 162.02 (d, J = 245.4 Hz)

19F NMR ( $\mathrm{CDCl}_{3}+$ Acetone-D6): -158.86 (dd, J = 19.4, 7.0 Hz), -141.84 (dd, J = 19.6, 7.8 Hz), -116.61 $-116.94(\mathrm{~m})$.

FT-IR $\left(\mathrm{cm}^{-1}\right): 690,771,804,821,894,1033,1078,1105,1163,1217,1288,1355,1365,1463,1498$, $1604,1635,1735,2850,2918,2970$

MS (ESI+): $707.1709\left(100 \%, 707.1709, \mathrm{C}_{45} \mathrm{H}_{55} \mathrm{~F}_{3} \mathrm{NaO}_{2}\right.$, calc. for $\left.\mathrm{C}_{45} \mathrm{H}_{55} \mathrm{~F}_{3} \mathrm{NaO}_{2} 707.4046\right)$

Assay (HPLC, C18, 230/265 nm): 99.4\%

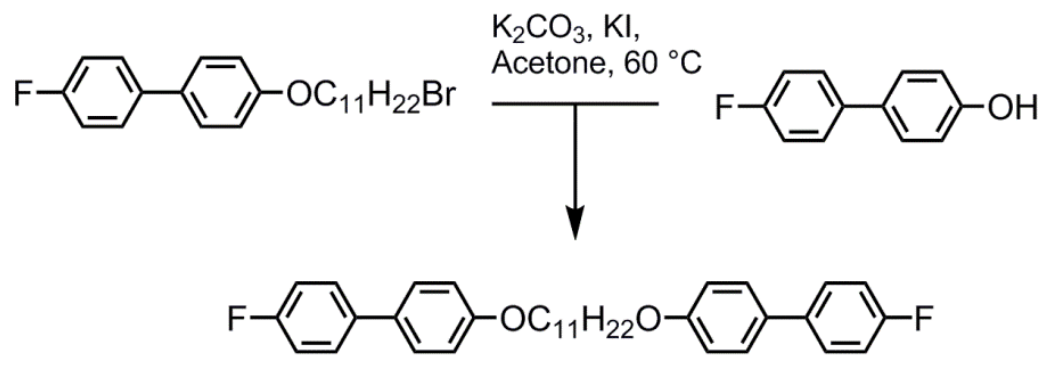

\section{1,11-bis((4'-Fluoro-[1,1'-biphenyl]-4-yl)oxy)undecane (12)}

Quantities used: i19 (613 mg, $3.26 \mathrm{mmol}), 1,11$-dibromoundecane (500 mg, $1.59 \mathrm{mmol}$ ), potassium carbonate $(690 \mathrm{mg}, 5 \mathrm{mmol})$, potassium iodide $(500 \mathrm{mg})$, acetone $(5 \mathrm{ml})$. The experimental procedure was as described for the synthesis of i3, with the title compound obtained via flash chromatography with 1:1 DCM/hexane as the eluent, followed by recrystallisation of the title compound from ethanol, giving the target material as a white powder.

Yield: $810 \mathrm{mg}(96 \%)$

${ }^{1} \mathrm{H}$ NMR $\left(\mathrm{CDCl}_{3}\right): 1.06-1.34\left(14 \mathrm{H}, \mathrm{m}, \mathrm{CH}_{2}-\left(\mathrm{CH}_{2}\right)_{7}-\mathrm{CH}_{2}\right), 1.59\left(4 \mathrm{H}\right.$, Quintet, $\mathrm{J}=6.4 \mathrm{~Hz}, \mathrm{ArOCH}_{2}-\mathrm{CH}_{2}-$ $\left.\left(\mathrm{CH}_{2}\right)_{7}-\mathrm{CH}_{2}-\mathrm{CH}_{2} \mathrm{OAr}\right), 3.78\left(4 \mathrm{H}, \mathrm{t}, \mathrm{J}=6.4 \mathrm{~Hz}, \mathrm{ArOCH}_{2}-\left(\mathrm{CH}_{2}\right)_{9}-\mathrm{CH}_{2} \mathrm{OAr}\right), 6.75(4 \mathrm{H}$, ddd, $J=1.8 \mathrm{~Hz}, \mathrm{~J}=$ $3.4 \mathrm{~Hz}, J=8.5 \mathrm{~Hz}, \mathrm{ArH}), 6.89(4 \mathrm{H}, \mathrm{dddd}, J=2.1 \mathrm{~Hz}, J=3.4 \mathrm{~Hz}, J=5.5 \mathrm{~Hz}, J=8.5 \mathrm{~Hz}, \operatorname{ArH}), 7.25(4 \mathrm{H}$, 
ddd, $J=1.8 \mathrm{~Hz}, J=3.4 \mathrm{~Hz}, J=8.5 \mathrm{~Hz}, \operatorname{ArH}), 7.29(4 \mathrm{H}, \mathrm{dddd}, J=2.1 \mathrm{~Hz}, J=3.4 \mathrm{~Hz}, J=5.5 \mathrm{~Hz}, J=8.5$ $\mathrm{Hz}, \mathrm{ArH})$

${ }^{13} \mathrm{C} \mathrm{NMR}\left(\mathrm{CDCl}_{3}\right): 25.50,28.73,28.82,28.93,28.98,67.55,114.33,114.98$ (d, J = $\left.21.5 \mathrm{~Hz}\right), 127.40$, 127.62 (d, $J=7.7 \mathrm{~Hz}), 131.87,136.45$ (d $J=3.1 \mathrm{~Hz}), 158.16,161.44$ (d, $J=244.7 \mathrm{~Hz})$

${ }^{19} \mathrm{~F} \mathrm{NMR}\left(\mathrm{CDCl}_{3}\right):-116.83(1 \mathrm{~F}, \mathrm{tt}, \mathrm{J}=4.6 \mathrm{~Hz}, \mathrm{~J}=9.2 \mathrm{~Hz}, \mathrm{ArF})$

FT-IR (cm-1): 717, 808, 821, 964, 1029, 1163, 1217, 1288, 1365, 1435, 1496, 1573, 1735, 2850, 2970, 3016

MS (ESI+): $551.2729\left(100 \%, \mathrm{C}_{35} \mathrm{H}_{38} \mathrm{~F}_{2} \mathrm{NaO}_{2}, \mathrm{M}+\mathrm{Na}\right.$, calc. for $\left.\mathrm{C}_{35} \mathrm{H}_{38} \mathrm{~F}_{2} \mathrm{NaO}_{2} 528.2840\right)$

Assay (HPLC, C18, 230/265 nm): 99.6\%

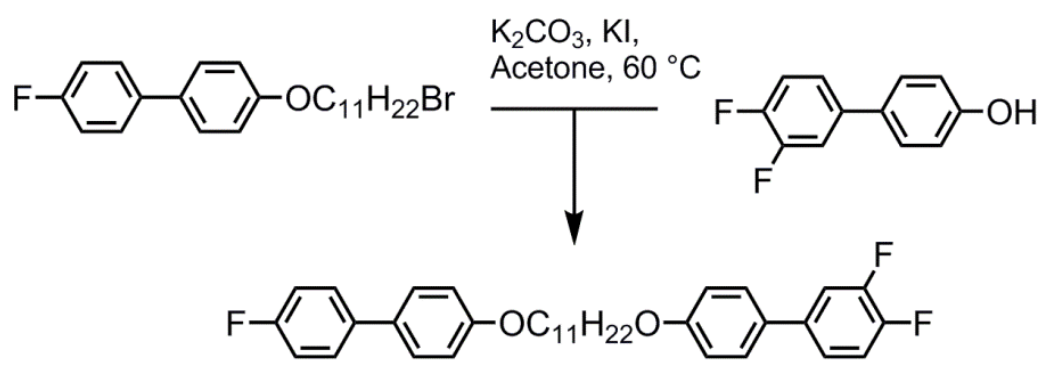

\section{3,4-Difluoro-4'-((11-((4'-fluoro-[1,1'-biphenyl]-4-yl)oxy)undecyl)oxy)-1,1'-biphenyl (13)}

Quantities used: i1 (154 mg, $0.748 \mathrm{mmol})$, i19 (300 mg, $0.712 \mathrm{mmol}$ ), potassium carbonate (197 mg, $200 \mathrm{mmol})$, potassium iodide $(250 \mathrm{mg})$, acetone $(5 \mathrm{ml})$. The experimental procedure was as described for the synthesis of $\mathbf{i} 3$, with the title compound obtained via flash chromatography with 1:1 DCM/hexane as the eluent, followed by recrystallisation of the title compound from ethanol, giving the target material as a file colourless solid.

Yield: $330 \mathrm{mg}(85 \%)$

${ }^{1} \mathrm{H}$ NMR $\left(\mathrm{CDCl}_{3}\right): 1.28$ - $1.53\left(14 \mathrm{H}, \mathrm{m}, \mathrm{CH}_{2}-\left(\mathrm{CH}_{2}\right)_{7}-\mathrm{CH}_{2}\right), 1.76-1.86\left(4 \mathrm{H}, \mathrm{m}, \mathrm{ArOCH}_{2}-\mathrm{CH}_{2}-\left(\mathrm{CH}_{2}\right)_{7}-\mathrm{CH}_{2}-\right.$ $\left.\mathrm{CH}_{2} \mathrm{OAr}\right)$, 3.96 - $4.02\left(4 \mathrm{H}, \mathrm{m}, \mathrm{ArOCH}_{2}-\left(\mathrm{CH}_{2}\right) 9-\mathrm{CH}_{2}-\mathrm{OAr}\right), 6.84-6.99(6 \mathrm{H}, \mathrm{m}, \mathrm{ArH}), 7.05-7.12(2 \mathrm{H}, \mathrm{m}$, $\mathrm{ArH}), 7.31-7.82(7 \mathrm{H}, \mathrm{m}, \mathrm{ArH})$

${ }^{13} \mathrm{C}$ NMR $\left(\mathrm{CDCl}_{3}\right): 26.01,29.32,29.25,29.34,29.48,29.51,32.79,33.99,67.99,68.04,104.09$ (d, $\mathrm{J}=$ $24.9 \mathrm{~Hz}$ ), 104.36 (d, J = 24.9 Hz), 111.39 (dd, J = 2.9 Hz, J = 20.1 Hz), 114.49, 114.77, 115.45 (d, J = $21.1 \mathrm{~Hz}$ ), 125.01 (dd, $J=2.9 \mathrm{~Hz}, J=13.4 \mathrm{~Hz}), 127.91,128.11$ (d, J = 8.6 Hz), 129.92 (d, J = $2.9 \mathrm{~Hz})$, 
131.05 (dd, $J=4.8 \mathrm{~Hz}, J=9.6 \mathrm{~Hz}$ ), 132.51, 136.98, 158.65, 158.79, 159.65 (dd, J = $11.5 \mathrm{~Hz}, J=249.2$ $\mathrm{Hz}), 161.75$ (dd, $J=12.5 \mathrm{~Hz}, J=248.2 \mathrm{~Hz}$ ), 162.00 (d, J = 246.3 Hz)

19F NMR $\left(\mathrm{CDCl}_{3}\right):-116.63(\mathrm{tt}, J=4.6 \mathrm{~Hz}, J=8.7 \mathrm{~Hz}, \operatorname{ArF}$ ), -113.64 (Quartet, $J=8.7 \mathrm{~Hz}),-112.27$ (Quintet, $J=8.7 \mathrm{~Hz}$ )

FT-IR (cm-1): 719, 763, 808, 821, 842, 906, 962, 1002, 1043, 1139, 1180, 1217, 1261, 1288, 1365, $1473,1492,1521,1573,1595,1735,2850,2918,2970,3016$

MS (ESI+): $585.2372\left(100 \%, \mathrm{C}_{35} \mathrm{H}_{37} \mathrm{~F}_{3} \mathrm{KO}_{2}, \mathrm{M}+\mathrm{K}\right.$, calc. for $\left.\mathrm{C}_{35} \mathrm{H}_{37} \mathrm{~F}_{3} \mathrm{KO} 585.2383\right), \quad 569.2664$ $\left(\mathrm{C}_{35} \mathrm{H}_{37} \mathrm{~F}_{3} \mathrm{NaO}_{2}, \mathrm{M}+\mathrm{Na}\right)$

Assay (HPLC, C18, 230/265 nm): 99.2\%

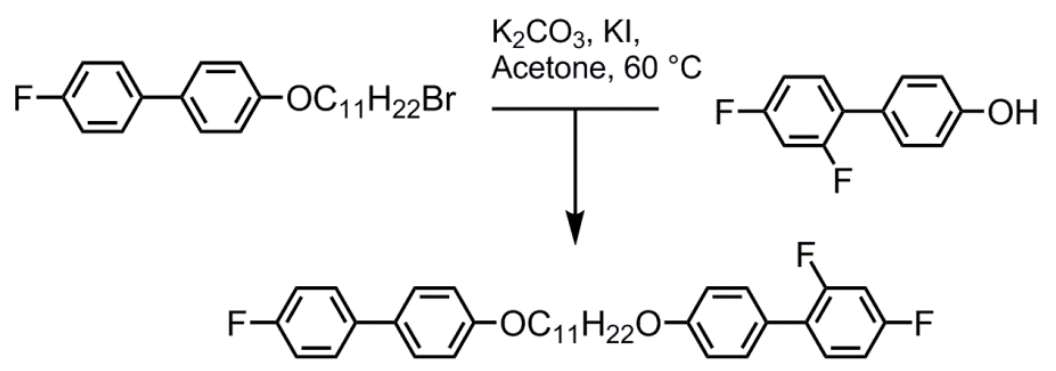

\section{2,4-Difluoro-4'-((11-((4'-fluoro-[1,1'-biphenyl]-4-yl)oxy)undecyl)oxy)-1,1'-biphenyl (14)}

Quantities used: i6 (154 mg, $0.748 \mathrm{mmol})$, i19 (300 mg, $0.712 \mathrm{mmol}$ ), potassium carbonate (197 mg, $200 \mathrm{mmol})$, potassium iodide $(250 \mathrm{mg})$, acetone $(5 \mathrm{ml})$. The experimental procedure was as described for the synthesis of $\mathrm{i} 3$, with the title compound obtained via flash chromatography with 1:1 DCM/hexane as the eluent, followed by recrystallisation of the title compound from ethanol, giving the target material as colourless plates.

Yield: $255 \mathrm{mg}(66 \%)$

${ }^{1} \mathrm{H}$ NMR $\left(\mathrm{CDCl}_{3}\right): 1.28$ - $1.52\left(14 \mathrm{H}, \mathrm{m}, \mathrm{CH}_{2}-\left(\mathrm{CH}_{2}\right)_{7}-\mathrm{CH}_{2}\right), 1.75-1.85\left(4 \mathrm{H}, \mathrm{m}, \mathrm{ArOCH}_{2}-\mathrm{CH}_{2}-\left(\mathrm{CH}_{2}\right)_{7}-\mathrm{CH}_{2}-\right.$ $\left.\mathrm{CH}_{2} \mathrm{OAr}\right), 3.96$ - $4.02\left(4 \mathrm{H}, \mathrm{m}, \mathrm{ArOCH}_{2}-\left(\mathrm{CH}_{2}\right) 9-\mathrm{CH}_{2}-\mathrm{OAr}\right), 6.92-6.98(4 \mathrm{H}, \mathrm{m}, \mathrm{ArH}), 7.05-7.12(2 \mathrm{H}, \mathrm{m}$, $\operatorname{ArH}), 7.13-7.27(2 \mathrm{H}, \mathrm{m}, \mathrm{ArH}), 7.32(1 \mathrm{H}, \mathrm{ddd}, J=2.3 \mathrm{~Hz}, J=7.8 \mathrm{~Hz}, J=11.5 \mathrm{~Hz}, \operatorname{ArH}), 7.39-7.51$ $(6 \mathrm{H}, \mathrm{m}, \mathrm{ArH})$

${ }^{13} \mathrm{C} \mathrm{NMR}\left(\mathrm{CDCl}_{3}\right): 26.02,29.23,29.26,29.35,29.43,29.48,29.51,32.80,34.04,68.06,68.09,114.83$ (d, $J=9.6 \mathrm{~Hz}), 115.47$ (d, $J=22.0 \mathrm{~Hz}), 117.36$ (d, $J=17.3 \mathrm{~Hz}), 122.39(\mathrm{~m}), 127.93$ (d, J = $1.9 \mathrm{~Hz}$ ), 
128.09, 128.18, 131.39, 132.56, 136.99 (d, $J=2.9 \mathrm{~Hz}$ ), 138.01 (Quartet, $J=3.8 \mathrm{~Hz}$ ), 149.14 (dd, $J=$ $12.5 \mathrm{~Hz}, J=247.3 \mathrm{~Hz}$ ), 150.37 (dd, $J=12.5 \mathrm{~Hz}, J=248.2 \mathrm{~Hz}$ ), 158.65, 159.06, 162.03 (d, J = 245.4 $\mathrm{Hz})$

${ }^{19} \mathrm{~F} \mathrm{NMR}\left(\mathrm{CDCl}_{3}\right):-141.40$ - -141.24 (1F, m, ArF), -137.82 - -137.64 (1F, m, $\left.\operatorname{ArF}\right),-116.76$ - -116.64 (1F, $\mathrm{m}, \operatorname{ArF})$

FT-IR (cm-1): 719, 744, 779, 806, 902, 964, 1029, 1124, 1163, 1217, 1365, 1489, 1533, 1575, 1602 , $1739,2850,2922,2970,3016$

MS (ESI+): $585.2366\left(\mathrm{C}_{35} \mathrm{H}_{37} \mathrm{~F}_{3} \mathrm{KO}_{2}, \mathrm{M}+\mathrm{K}\right), 569.2651\left(100 \%, \mathrm{C}_{35} \mathrm{H}_{37} \mathrm{~F}_{3} \mathrm{NaO}_{2}, \mathrm{M}+\mathrm{Na}\right.$, Calc for $\mathrm{C}_{35} \mathrm{H}_{37} \mathrm{~F}_{3} \mathrm{NaO}_{2}$ 569.2638)

Assay (HPLC, C18, 230/265 nm): 99.3\%

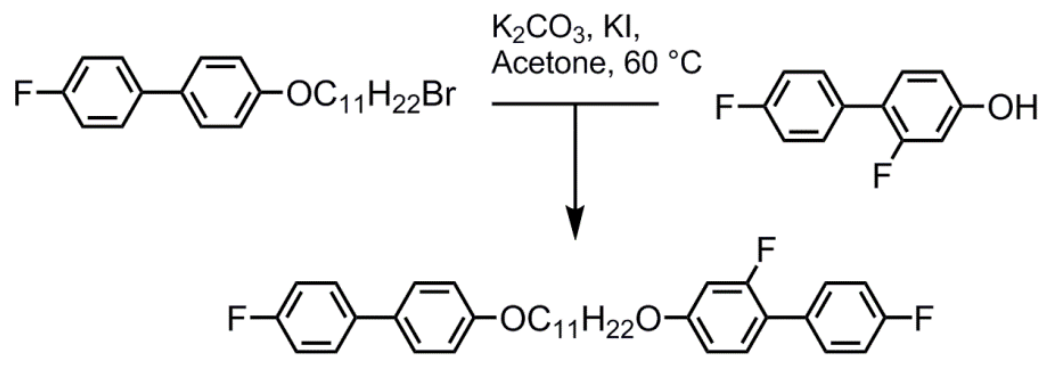

\section{2,4'-Difluoro-4-((11-((4'-fluoro-[1,1'-biphenyl]-4-yl)oxy)undecyl)oxy)-1,1'-biphenyl (15)}

Quantities used: i7 (154 mg, $0.748 \mathrm{mmol})$, i19 (300 mg, $0.712 \mathrm{mmol}$ ), potassium carbonate (197 mg, $200 \mathrm{mmol})$, potassium iodide $(250 \mathrm{mg})$, acetone $(5 \mathrm{ml})$. The experimental procedure was as described for the synthesis of $i 3$, with the title compound obtained via flash chromatography with 1:1 DCM/hexane as the eluent, followed by recrystallisation of the title compound from ethanol, giving the target material as colourless plates.

Yield: $320 \mathrm{mg}(82 \%)$

${ }^{1} \mathrm{H} \mathrm{NMR}\left(\mathrm{CDCl}_{3}\right): 1.26$ - $1.54\left(14 \mathrm{H}, \mathrm{m}, \mathrm{CH}_{2}-\left(\mathrm{CH}_{2}\right)_{7}-\mathrm{CH}_{2}\right), 1.75-1.84\left(4 \mathrm{H}, \mathrm{m}, \mathrm{ArOCH}_{2}-\mathrm{CH}_{2}-\left(\mathrm{CH}_{2}\right)_{7}-\mathrm{CH}_{2}-\right.$ $\mathrm{CH}_{2} \mathrm{OAr}$ '), $3.76\left(2 \mathrm{H}, \mathrm{t}, \mathrm{J}=6.4 \mathrm{~Hz}, \mathrm{ArOCH}_{2}-\left(\mathrm{CH}_{2}\right)_{9}-\mathrm{CH}_{2} \mathrm{OAr}\right), 3.99\left(2 \mathrm{H}, \mathrm{t}, \mathrm{J}=6.4 \mathrm{~Hz}, \mathrm{ArOCH}_{2}-\left(\mathrm{CH}_{2}\right)_{9}-\right.$ $\left.\mathrm{CH}_{2}-\mathrm{OAr}\right), 6.70(2 \mathrm{H}, \mathrm{dddd}, J=2.3 \mathrm{~Hz}, J=2.8 \mathrm{~Hz}, J=8.5 \mathrm{~Hz}, J=10.5 \mathrm{~Hz}, \operatorname{ArH}), 6.95(4 \mathrm{H}, \mathrm{dddd}, J=$ $2.2 \mathrm{~Hz}, J=2.8 \mathrm{~Hz}, J=8.7 \mathrm{~Hz}, \operatorname{ArH}), 7.06-7.13(4 \mathrm{H}, \mathrm{m}, \mathrm{ArH}), 7.28(1 \mathrm{H}, \mathrm{t}, J=9.2 \mathrm{~Hz}, \operatorname{ArH}), 7.43-7.52$ $(4 \mathrm{H}, \mathrm{m}, \mathrm{ArH})$ 
${ }^{13} \mathrm{C}$ NMR $\left(\mathrm{CDCl}_{3}\right): 25.71,26.03,29.08,29.26,29.31,29.35,29.47,29.51,68.07,68.40,102.47$ (d, $\mathrm{J}=$ $25.9 \mathrm{~Hz}), 110.84$ (d, J = 2.9 Hz), 114.78, 115.26 (d, J = 20.6 Hz), 115.46 (d, J = 20.1 Hz), 120.12 (d, J = $13.4 \mathrm{~Hz}$ ), 127.94, 128.13 (d, J = 7.7 Hz), 130.31 (dd, J = 2.9 Hz, J = 7.7 Hz), 130.77 (d, J = 5.8 Hz), 132.55, 136.69 (d, J = 2.9 Hz), 158.66, 158.65, 158.89, 159.80 (d, J = 10.5 Hz), 160.80, 161.32, 163.25 $(\mathrm{d}, J=1.9 \mathrm{~Hz})$

19F NMR $\left(\mathrm{CDCl}_{3}\right):-116.70(1 \mathrm{~F}, \mathrm{tt}, J=4.4 \mathrm{~Hz}, J=8.7 \mathrm{~Hz}, \operatorname{ArF}),-115.87(1 \mathrm{~F}, \mathrm{t}, J=10.1 \mathrm{~Hz}, \operatorname{ArF}),-115.39$ $(1 \mathrm{~F}, \mathrm{tt}, J=5.6 \mathrm{~Hz}, J=8.7 \mathrm{~Hz}, \operatorname{ArF})$

FT-IR (cm-1): 781, 819, 842, 964, 999, 1031, 1128, 1163, 1205, 1288, 1365, 1456, 1494, 1521, 1602, $1624,1743,2850,2970$

MS (ESI+): $585.2365\left(100 \%, \mathrm{C}_{35} \mathrm{H}_{37} \mathrm{~F}_{3} \mathrm{KO}_{2}, \mathrm{M}+\mathrm{K}\right.$, calc. for $\left.\mathrm{C}_{35} \mathrm{H}_{37} \mathrm{~F}_{3} \mathrm{KO}_{2} 585.2382\right), \quad 569.2638$ $\left(\mathrm{C}_{35} \mathrm{H}_{37} \mathrm{~F}_{3} \mathrm{NaO}_{2}, \mathrm{M}+\mathrm{Na}\right)$

Assay (HPLC, C18, 230/265 nm): 99.2\%

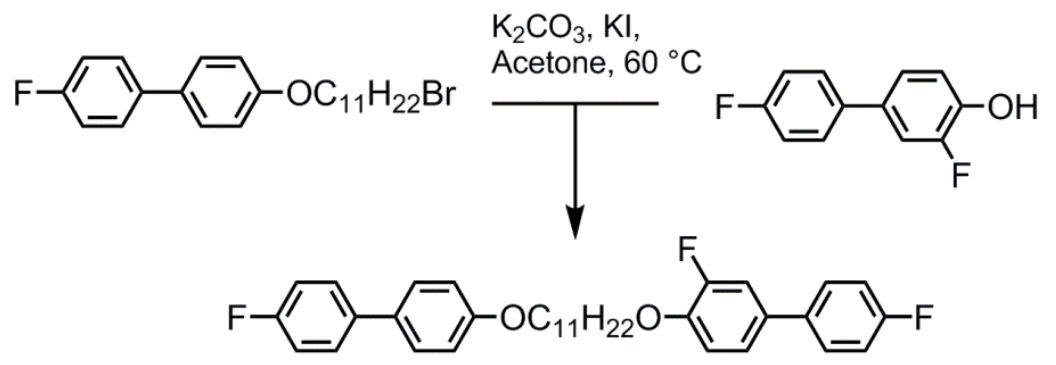

\section{3,4'-Difluoro-4-((11-((4'-fluoro-[1,1'-biphenyl]-4-yl)oxy)undecyl)oxy)-1,1'-biphenyl (16)}

Quantities used: i8 (154 mg, $0.748 \mathrm{mmol})$, i19 (300 mg, $0.712 \mathrm{mmol}$ ), potassium carbonate (197 mg, $200 \mathrm{mmol})$, potassium iodide $(250 \mathrm{mg})$, acetone $(5 \mathrm{ml})$. The experimental procedure was as described for the synthesis of $i 3$, with the title compound obtained via flash chromatography with 1:1 DCM/hexane as the eluent, followed by recrystallisation of the title compound from ethanol, giving the target material as colourless plates.

Yield: $275 \mathrm{mg}(71 \%)$

${ }^{1} \mathrm{H}$ NMR $\left(\mathrm{CDCl}_{3}\right): 1.21-1.46\left(14 \mathrm{H}, \mathrm{m}, \mathrm{CH}_{2}-\left(\mathrm{CH}_{2}\right)_{7}-\mathrm{CH}_{2}\right), 1.68-1.80\left(4 \mathrm{H}, \mathrm{m}, \mathrm{ArOCH}_{2}-\mathrm{CH}_{2}-\left(\mathrm{CH}_{2}\right)_{7}-\mathrm{CH}_{2}-\right.$ $\left.\mathrm{CH}_{2} \mathrm{OAr}\right), 3.90\left(2 \mathrm{H}, \mathrm{t}, J=6.7 \mathrm{~Hz}, \operatorname{ArOCH}_{2}-\left(\mathrm{CH}_{2}\right)_{9}-\mathrm{CH}_{2} \mathrm{OAr}^{\prime}\right), 3.97\left(2 \mathrm{H}, \mathrm{t}, J=6.7 \mathrm{~Hz}, \operatorname{ArOCH}_{2}-\left(\mathrm{CH}_{2}\right)_{9}-\right.$ $\mathrm{CH}_{2}-\mathrm{OAr}$ ) $, 6.87(2 \mathrm{H}, \mathrm{ddd}, \mathrm{J}=1.8 \mathrm{~Hz}, J=3.2 \mathrm{~Hz}, \mathrm{~J}=8.7 \mathrm{~Hz}, \mathrm{ArH}), 6.91(1 \mathrm{H}, \mathrm{t}, J=8.2 \mathrm{~Hz}, \operatorname{ArH}), 6.97-$ 
$7.04(4 \mathrm{H}, \mathrm{mf}, \mathrm{ArH}), 7.11-7.15(1 \mathrm{H}, \mathrm{m}, \mathrm{ArH}), 7.19(1 \mathrm{H}, \mathrm{dd}, J=2.3 \mathrm{~Hz}, J=12.4 \mathrm{~Hz}, \operatorname{ArH}), 7.35-7.43$ $(6 \mathrm{H}, \mathrm{m}, \mathrm{ArH})$

${ }^{13} \mathrm{C} \mathrm{NMR}\left(\mathrm{CDCl}_{3}\right): 25.89,26.01,29.19,29.26,29.31,29.35,29.46,29.48,29.50,66.07,69.53,114.60$, 114.76, 115.12 (d, J = 1.9 Hz), 155.45 (dd, J = $18.2 \mathrm{~Hz}, J=21.1 \mathrm{~Hz}), 122.42$ (d, J = 2.9 Hz), 127.94, $128.12(\mathrm{~d}, J=5.8 \mathrm{~Hz}), 128.20$ (d, $J=4.8 \mathrm{~Hz}), 132.54,133.29$ (d, $J=6.7 \mathrm{~Hz}), 135.89$ (t, $J=1.9 \mathrm{~Hz})$, 136.99 (d, J = 3.8 Hz), 146.51 (d, J = 10.5 Hz), 151.57, 154.01, 158.66, 160.93 (d, J = 25.9 Hz), 162.22 (dd, $J=26.8 \mathrm{~Hz}, J=246.3 \mathrm{~Hz}$ )

19F NMR $\left(\mathrm{CDCl}_{3}\right):-134.03(1 \mathrm{~F}, \mathrm{dd}, J=8.7 \mathrm{~Hz}, J=11.6 \mathrm{~Hz}, \operatorname{ArF}),-116.71(1 \mathrm{~F}, \mathrm{tt}, J=4.3 \mathrm{~Hz}, J=8.7 \mathrm{~Hz}$, $\operatorname{ArF}),-115.69(1 \mathrm{~F}, \mathrm{tt}, J=5.8 \mathrm{~Hz}, J=8.7 \mathrm{~Hz}, \operatorname{Ar} F)$

FT-IR (cm-1): 669, 719, 806, 839, 875, 896, 964, 1014, 1134, 1163, 1217, 1280, 1296, 1371, 1435, $1558,1602,1739,2850,2970,3005$

MS (ESI+): $585.2381\left(\mathrm{C}_{35} \mathrm{H}_{37} \mathrm{~F}_{3} \mathrm{KO}_{2}, \mathrm{M}+\mathrm{K}\right), 569.2651\left(100 \%, \mathrm{C}_{35} \mathrm{H}_{37} \mathrm{~F}_{3} \mathrm{NaO}_{2}, \mathrm{M}+\mathrm{Na}\right.$, Calc for $\mathrm{C}_{35} \mathrm{H}_{37} \mathrm{~F}_{3} \mathrm{NaO}_{2}$ 569.2638)

Assay (HPLC, C18, 230/265 nm): 99.4\%

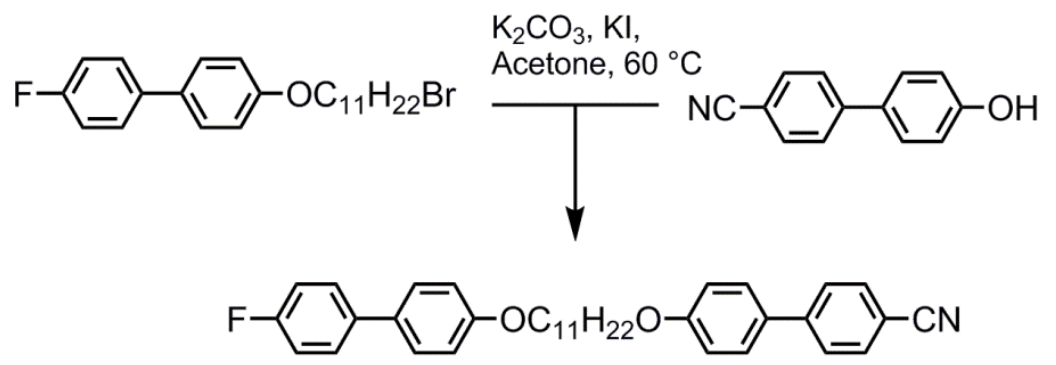

\section{4'-((11-((4'-Fluoro-[1,1'-biphenyl]-4-yl)oxy)undecyl)oxy)-[1,1'-biphenyl]-4-carbonitrile (17)}

Quantities used: i12 (146 mg, $0.748 \mathrm{mmol})$, i19 (300 mg, $0.712 \mathrm{mmol})$, potassium carbonate $(197 \mathrm{mg}$, $1.424 \mathrm{mmol})$, potassium iodide $(1 \mathrm{~g})$, acetone $(25 \mathrm{ml})$. The experimental procedure was as described for the synthesis of $\mathrm{i} 3$, with the title compound obtained via flash chromatography with 1:1 DCM/hexane as the eluent, followed by recrystallisation of the title compound from ethanol, giving the target material as a white solid.

Yield: $180 \mathrm{mg}$ 
${ }^{1} \mathrm{H}$ NMR (CDCl $): 1.21$ - 1.44 (14H, m, ArO- $\left.\mathrm{CH}_{2}-\mathrm{CH}_{2}-\left(\mathrm{CH}_{2}\right)_{7}-\mathrm{CH}_{2}-\mathrm{CH}_{2}-\mathrm{OAr}\right)$, 1.68 - 1.77 (4H, m, ArO$\left.\left.\mathrm{CH}_{2}-\mathrm{CH}_{2}-\left(\mathrm{CH}_{2}\right)_{7}-\mathrm{CH}_{2}-\mathrm{CH}_{2}-\mathrm{OAr}\right)^{\prime}\right), 3.88-3.94$ (4H, m, ArO- $\left.\mathrm{CH}_{2}-\left(\mathrm{CH}_{2}\right)_{7}-\mathrm{CH}_{2}-\mathrm{OAr}{ }^{\prime}\right), 6.85-6.93$ (4H, m, $\operatorname{ArH}), 6.97-7.04(2 \mathrm{H}, \mathrm{ddt}, J=1.8 \mathrm{~Hz}, J=3.2 \mathrm{~Hz}, J=8.7 \mathrm{~Hz}, \mathrm{ArH}), 7.34-7.46(6 \mathrm{H}, \mathrm{m}, \mathrm{ArH}), 7.52-$ $7.56(2 \mathrm{H}, \mathrm{m}, \mathrm{ArH}), 7.57-7.63(2 \mathrm{H}, \mathrm{m}, \mathrm{ArH})$.

${ }^{13} \mathrm{C} \operatorname{NMR}\left(\mathrm{CDCl}_{3}\right): 25.99,26.00,29.18,29.24,29.33,29.46,29.49,68.04,68.12,109.97,114.76$, 115.47 (d, $J=22.0 \mathrm{~Hz}$ ), 115.57,119.08, 127.00, 127.92, 128.11 (d, $J=7.7 \mathrm{~Hz}), 128.27,131.18,132.51$, $132.53,136.95$ (d, J = 3.8 Hz), 145.22, 158.63, 159.76, 162.01 (d, J = 245.4 Hz)

${ }^{19} \mathrm{~F} \mathrm{NMR}\left(\mathrm{CDCl}_{3}\right):-116.65(1 \mathrm{~F}, \mathrm{tt}, \mathrm{J}=4.3 \mathrm{~Hz}, J=8.7 \mathrm{~Hz}, \mathrm{ArF})$

FT-IR (cm-1): 661, 779, 817, 850, 964, 1116, 1217, 1288, 1365, 1435, 1494, 1558, 1600, 1735, 2235, $2850,2929,2970,3005$

MS (ESI+): $574.2534\left(\mathrm{C}_{36} \mathrm{H}_{38} \mathrm{FKNO}_{2}, \mathrm{M}+\mathrm{K}\right), 558.2787\left(100 \%, \mathrm{C}_{36} \mathrm{H}_{38} \mathrm{FNNaO}_{2}, \mathrm{M}+\mathrm{Na}\right.$, Calc. for $\mathrm{C}_{36} \mathrm{H}_{38} \mathrm{FNNaO}_{2}$ 558.2779)

Assay (HPLC, C18, 230/265 nm): 99.1\%

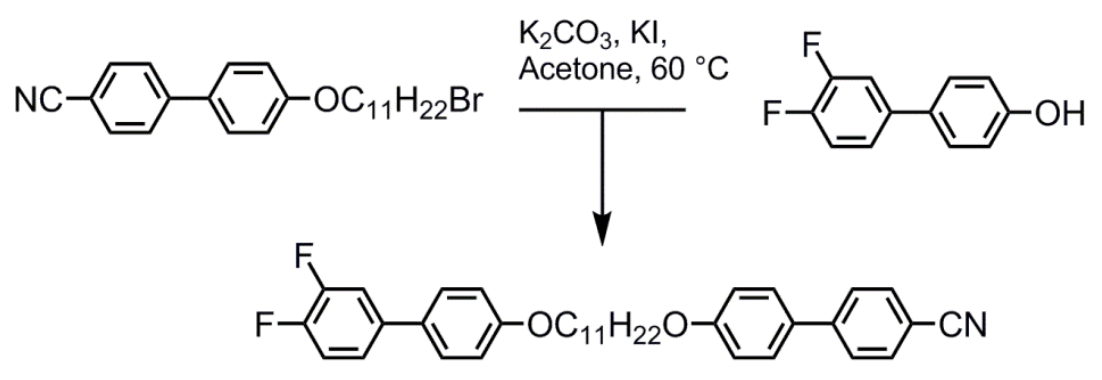

\section{4'-((11-((3',4'-difluoro-[1,1'-biphenyl]-4-yl)oxy)undecyl)oxy)-[1,1'-biphenyl]-4-carbonitrile (18)}

Quantities used: i15 (500 mg, $1.168 \mathrm{mmol})$, i1 (282 mg, $1.370 \mathrm{mmol}), \mathrm{K}_{2} \mathrm{CO}_{3}(500 \mathrm{mg}, 3.62 \mathrm{mmol}), \mathrm{KI}$ $(1 \mathrm{~g})$, acetone $(15 \mathrm{ml})$. The experimental procedure was as described in the synthesis of compound $\mathrm{i} 3$, with the title compound isolated via flash chromatography with DCM as the eluent followed by recrystalisation from ethanol.

Yield: $610 \mathrm{mg}(94 \%)$

${ }^{1} \mathrm{H}$ NMR $\left(\mathrm{CDCl}_{3}\right): 1.21$ - 1.45 (14H, m, ArO- $\left.\left(\mathrm{CH}_{2}\right)_{2}-\left(\mathrm{CH}_{2}\right)_{7}-\left(\mathrm{CH}_{2}\right)_{2}-\mathrm{OAr}\right), 1.68$ - 1.79 (4H, m, ArO- $\mathrm{CH}_{2}-$ $\left.\left.\left.\mathrm{CH}_{2}-\left(\mathrm{CH}_{2}\right)_{7}-\mathrm{CH}_{2}-\mathrm{CH}_{2}-\mathrm{OAr}\right)^{\prime}\right), 3.88-3.95\left(4 \mathrm{H}, \mathrm{m}[\mathrm{t}+\mathrm{t}], \mathrm{ArO}-\mathrm{CH}_{2}-\left(\mathrm{CH}_{2}\right)_{9}-\mathrm{CH}_{2}-\mathrm{OAr}\right)^{\prime}\right), 6.88(2 \mathrm{H}, \mathrm{ddd}, \mathrm{J}=$ $1.8 \mathrm{~Hz}, J=3.2 \mathrm{~Hz}, J=8.7 \mathrm{~Hz}, \operatorname{ArH}), 6.92(2 \mathrm{H}, \mathrm{ddd}, J=2.3 \mathrm{~Hz}, J=2.8 \mathrm{~Hz}, J=9.2 \mathrm{~Hz}, \operatorname{ArH}), 7.06-7.18$ 
$(2 \mathrm{H}, \mathrm{m}, \mathrm{ArH}), 7.25(1 \mathrm{H}, \mathrm{ddd}, J=2.3 \mathrm{~Hz}, J=7.8 \mathrm{~Hz}, J=11.9 \mathrm{~Hz}, \mathrm{ArH}), 7.36(2 \mathrm{H}, \mathrm{ddd}, J=2.3 \mathrm{~Hz}, J=2.8$ $\mathrm{Hz}, J=9.2 \mathrm{~Hz}, \operatorname{ArH}), 7.44(2 \mathrm{H}, \mathrm{ddd}, J=1.8 \mathrm{~Hz}, J=3.2 \mathrm{~Hz}, J=8.7 \mathrm{~Hz}, \operatorname{ArH}), 7.56(2 \mathrm{H}, \mathrm{m}, \operatorname{ArH}), 7.61$ $(2 \mathrm{H}, \mathrm{m}, \mathrm{ArH})$

${ }^{13} \mathrm{C}$ NMR $\left(\mathrm{CDCl}_{3}\right): 26.00,29.18,29.21,29.33,29.46,29.49,68.07,68.11,109.97,114.85,115.02$, 115.40 (d, $J=18.2 \mathrm{~Hz}$ ), 117.36 (d, $J=17.3 \mathrm{~Hz}$ ), 119.10, 122.38 (quartet, $J=2.9 \mathrm{~Hz}$ ), 127.01, 127.91, 128.27, 131.29 (d, $J=18.2 \mathrm{~Hz}), 132.59,138.0(\mathrm{~m}), 145.22,149.25$ (dd, $J=12.5 \mathrm{~Hz}, J=234.8 \mathrm{~Hz}$ ), $150.71(\mathrm{dd}, J=13.4 \mathrm{~Hz}, \mathrm{~J}=247.3 \mathrm{~Hz}$ ), $159.0,159.75$

19F NMR (CDCl $\left.)_{3}\right):-141.37--141.22(1 \mathrm{~F}, \mathrm{~m}, \mathrm{ArF}),-137.73(1 \mathrm{~F}, \mathrm{tt}, \mathrm{J}=8.7 \mathrm{~Hz}, \mathrm{~J}=11.6 \mathrm{~Hz}, \mathrm{ArF})$

FT-IR (cm-1): 663, 717, 746, 779, 813, 837, 867, 902, 964, 1020, 1029, 1124, 1182, 1230, 1249, 1282, $1305,1394,1462,1504,1535,1604,2235,2850,2922$

MS (ESI+): $592.2412\left(\mathrm{C}_{36} \mathrm{H}_{37} \mathrm{~F}_{2} \mathrm{NKO}_{2}, \mathrm{M}+\mathrm{K}\right), 576.2664\left(100 \%, \mathrm{C}_{36} \mathrm{H}_{37} \mathrm{~F}_{2} \mathrm{NNaO}_{2}, \mathrm{M}+\mathrm{Na}\right.$, Calc. for $\mathrm{C}_{36} \mathrm{H}_{37} \mathrm{~F}_{2} \mathrm{NNaO}_{2}$ 576.2685)

Assay (HPLC, C18, 230/265 nm): 99.1\%

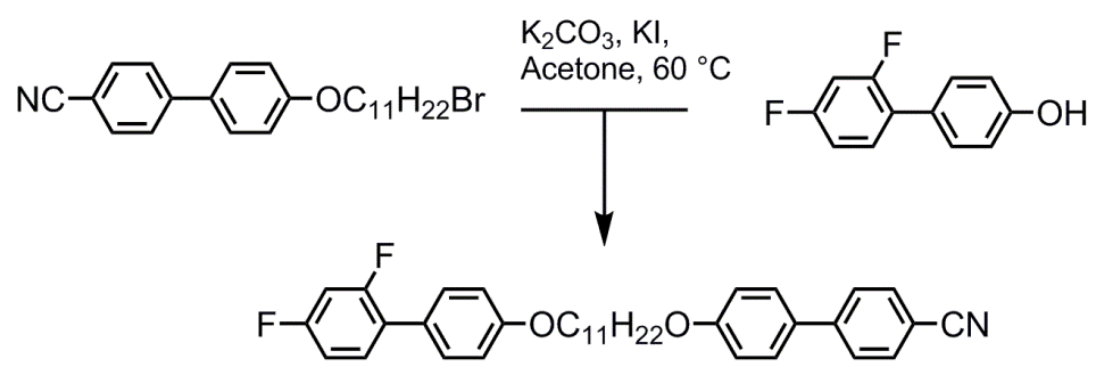

4'-((11-((2',4'-difluoro-[1,1'-biphenyl]-4-yl)oxy)undecyl)oxy)-[1,1'-biphenyl]-4-carbonitrile

Quantities used: i15 (500 mg, $1.168 \mathrm{mmol})$, i6 (282 mg, $1.370 \mathrm{mmol}), \mathrm{K}_{2} \mathrm{CO}_{3}((500 \mathrm{mg}, 3.62 \mathrm{mmol}), \mathrm{KI}$ $(1 \mathrm{~g})$, acetone $(15 \mathrm{ml})$. The experimental procedure was as described in the synthesis of compound $\mathrm{i} 3$, with the title compound isolated via flash chromatography with DCM as the eluent followed by recrystalisation from ethanol.

Yield: $500 \mathrm{mg}(77 \%)$

${ }^{1} \mathrm{H}$ NMR $\left(\mathrm{CDCl}_{3}\right): 1.21-1.45\left(14 \mathrm{H}, \mathrm{m},-\mathrm{CH}_{2}-\left(\mathrm{CH}_{2}\right)_{7}-\mathrm{CH}_{2}-\right), 1.68-1.79\left(4 \mathrm{H}, \mathrm{ArOCH}_{2}-\mathrm{CH}_{2-}-\left(\mathrm{CH}_{2}\right)_{7}-\mathrm{CH}_{2}-\right.$ $\left.\mathrm{CH}_{2}-\mathrm{OAr}\right), 3.90-3.96\left(4 \mathrm{H}, \mathrm{m}, \mathrm{ArOCH}_{2}+\mathrm{Ar}^{\prime} \mathrm{OCH}_{2}\right), 6.77-6.95(6 \mathrm{H}, \mathrm{m}, \mathrm{ArH}), 7.24-7.36(3 \mathrm{H}, \mathrm{m}$, $\operatorname{Ar} H), 7.45(2 \mathrm{H}, \mathrm{ddd}, H=1.8 \mathrm{~Hz}, J=2.7 \mathrm{~Hz}, J=8.7 \mathrm{~Hz}, \operatorname{ArH}), 7.56(2 \mathrm{H}, \mathrm{ddd}, H=1.8 \mathrm{~Hz}, J=2.7 \mathrm{~Hz}, J=$ $8.7 \mathrm{~Hz}, \operatorname{ArH}), 7.62(2 \mathrm{H}, \mathrm{ddd}, H=1.8 \mathrm{~Hz}, J=2.7 \mathrm{~Hz}, J=8.7 \mathrm{~Hz}, \mathrm{ArH})$ 
${ }^{13} \mathrm{C} \mathrm{NMR}\left(\mathrm{CDCl}_{3}\right): 26.00,26.02,29.18,29.22,29.34,29.47,29.50,68.00,68.13,104.11$ (d, $J=24.9$ $\mathrm{Hz}), 104.38$ (d, $J=24.9 \mathrm{~Hz}), 109.98,111.42$ (dd, $J=3.8 \mathrm{~Hz}, J=21.1 \mathrm{~Hz}), 114.49,115.03,119.11$, 125.00 (dd, $J=3.8 \mathrm{~Hz}, J=14.4 \mathrm{~Hz}$ ), 127.03, 128.29, 129.94 (d, $J=2.9 \mathrm{~Hz}), 131.04$ (d, J = 4.8 Hz), 131.17 (d, $J=6.7 \mathrm{~Hz}), 132.53,145.24,158.78,159.77,161.88$ (dd, $J=11.5 \mathrm{~Hz}, J=224.3 \mathrm{~Hz}$ )

19F NMR $\left(\mathrm{CDCl}_{3}\right):-113.75$ (Quartet, $\left.J=6.7 \mathrm{~Hz}, \operatorname{ArF}\right),-112.31$ (Quintet, $J=6.7 \mathrm{~Hz}, \operatorname{ArF}$ )

FT-IR (cm-1): 661, 719, 732, 781, 808, 823, 850, 962, 1001, 1041, 1099, 1139, 1178, 1240, 1292, 1390, $1433,1473,1490,1519,1606,1739,2231,2850,2918$

MS (ESI+): $576.2677\left(100 \%, \mathrm{C}_{36} \mathrm{H}_{37} \mathrm{~F}_{2} \mathrm{NNaO}_{2}, \mathrm{M}+\mathrm{Na}\right.$, Calc. for $\left.\mathrm{C}_{36} \mathrm{H}_{37} \mathrm{~F}_{2} \mathrm{NNaO}_{2} 576.2685\right)$

Assay (HPLC, C18, 230/265 nm): 99.3\%

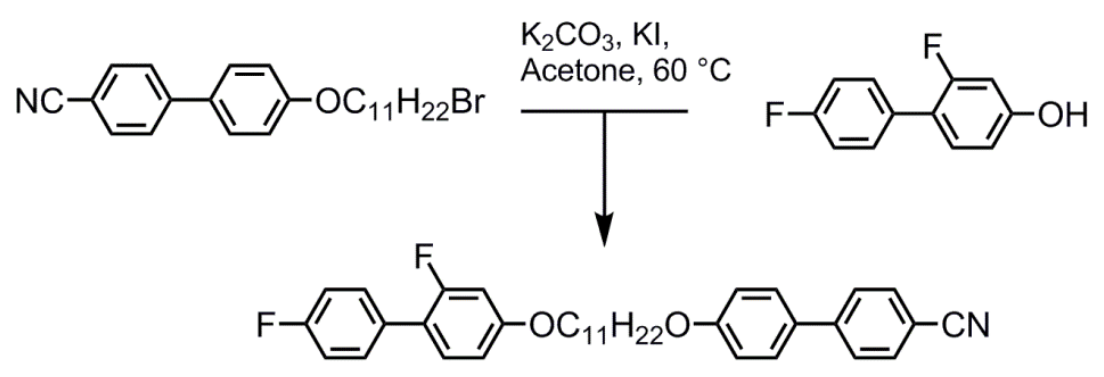

4'-((11-((3,4'-difluoro-[1,1'-biphenyl]-4-yl)oxy)undecyl)oxy)-[1,1'-biphenyl]-4-carbonitrile (20)

Quantities used: i15 (500 mg, $1.168 \mathrm{mmol})$, i7 (282 mg, $1.370 \mathrm{mmol}), \mathrm{K}_{2} \mathrm{CO}_{3}(500 \mathrm{mg}, 3.62 \mathrm{mmol}), \mathrm{KI}$ $(1 \mathrm{~g})$, acetone $(15 \mathrm{ml})$. The experimental procedure was as described in the synthesis of compound $\mathrm{i} 3$, with the title compound isolated via flash chromatography with DCM as the eluent followed by recrystalisation from ethanol.

Yield: $570 \mathrm{mg}(88 \%)$

${ }^{1} \mathrm{H}$ NMR $\left(\mathrm{CDCl}_{3}\right): 1.20-1.45\left(14 \mathrm{H}, \mathrm{m},-\mathrm{CH}_{2}-\left(\mathrm{CH}_{2}\right)_{7}-\mathrm{CH}_{2}-\right), 1.65-1.78\left(\mathrm{ArOCH}_{2}-\mathrm{CH}_{2}-\left(\mathrm{CH}_{2}\right)_{7}-\mathrm{CH}_{2}-\right.$ $\left.\mathrm{CH}_{2} \mathrm{OAr}\right), 3.88\left(2 \mathrm{H}, \mathrm{t}, \mathrm{J}=6.9 \mathrm{~Hz}, \mathrm{ArOCH}_{2}\right), 3.92\left(2 \mathrm{H}, \mathrm{t}, J=6.9 \mathrm{~Hz}, \mathrm{ArOCH}_{2}\right), 6.64(2 \mathrm{H}, \mathrm{ddd}, J=2.3 \mathrm{~Hz}$, $J=8.2 \mathrm{~Hz}, J=19.7 \mathrm{~Hz}, \operatorname{ArH}), 6.91(2 \mathrm{H}, \mathrm{ddd}, J=1.8 \mathrm{~Hz}, H=2.7 \mathrm{~Hz}, J=9.2 \mathrm{~Hz}, \operatorname{ArH}), 6.98(2 \mathrm{H}, \mathrm{m}$, $\operatorname{ArH}), 7.20(1 \mathrm{H}, \mathrm{t}, J=8.7 \mathrm{~Hz}, \operatorname{ArH}), 7.34-7.40(2 \mathrm{H}, \mathrm{m}, \mathrm{ArH}), 7.44(2 \mathrm{H}, \mathrm{ddd}, J=1.8 \mathrm{~Hz}, H=2.7 \mathrm{~Hz}, J=$ $9.2 \mathrm{~Hz}, \operatorname{ArH}), 7.54(2 \mathrm{H}, \mathrm{ddd}, J=1.8 \mathrm{~Hz}, H=2.7 \mathrm{~Hz}, J=9.2 \mathrm{~Hz}, \operatorname{Ar} H), 7.60(2 \mathrm{H}, \mathrm{ddd}, J=1.8 \mathrm{~Hz}, H=2.7$ $\mathrm{Hz}, J=9.2 \mathrm{~Hz}, \mathrm{ArH})$. 
${ }^{13} \mathrm{C} \mathrm{NMR}\left(\mathrm{CDCl}_{3}\right): 25.92,26.00,29.07,29.18,29.30,29.33,29.46,29.49,68.11,68.38,102.44$ (d, $\mathrm{J}=$ $26.84 \mathrm{~Hz}$ ), 109.96, 110.81 (d, $J=2.9 \mathrm{~Hz}), 115.02,115.27$ (d, J = 21.1 Hz), 119.09, 120.09 (d, J = 14.4 $\mathrm{Hz}), 127.63$ (d, $J=127.5 \mathrm{~Hz}$ ), 130.28 (dd, $J=2.9 \mathrm{~Hz}, J=7.7 \mathrm{~Hz}), 130.75$ (d, J = 5.8 Hz), 131.19, 131.73 (d, $J=1.9 \mathrm{~Hz}), 132.52,145.22,159.75,159.77$ (d, $J=11.5 \mathrm{~Hz}), 160.09$ (d, J = 247.3 Hz), $162.01(\mathrm{~d}, \mathrm{~J}=246.3 \mathrm{~Hz})$

19F NMR $\left(\mathrm{CDCl}_{3}\right):-115.85(\mathrm{t}, J=11.6 \mathrm{~Hz}, \operatorname{ArF}),-115.34(\mathrm{tt}, J=5.8 \mathrm{~Hz}, J=8.7 \mathrm{~Hz}, \operatorname{ArF})$

FT-IR (cm-1): 661, 723, 781, 817, 846, 952, 1026, 1041, 1109, 1163, 1180, 1222, 1249, 1305, 1319, $1473,1494,1521,1570,1604,1624,1739,2227,2850,2914,2937$

MS (ESI+): $592.2435\left(\mathrm{C}_{36} \mathrm{H}_{37} \mathrm{~F}_{2} \mathrm{NKO}_{2}, \mathrm{M}+\mathrm{K}\right), \quad\left(100 \%, \mathrm{C}_{36} \mathrm{H}_{37} \mathrm{~F}_{2} \mathrm{NNaO}_{2}, \mathrm{M}+\mathrm{Na}\right.$, Calc. for $\mathrm{C}_{36} \mathrm{H}_{37} \mathrm{~F}_{2} \mathrm{NNaO}_{2}$ 576.2685)

Assay (HPLC, C18, 230/265 nm): 99.3\%

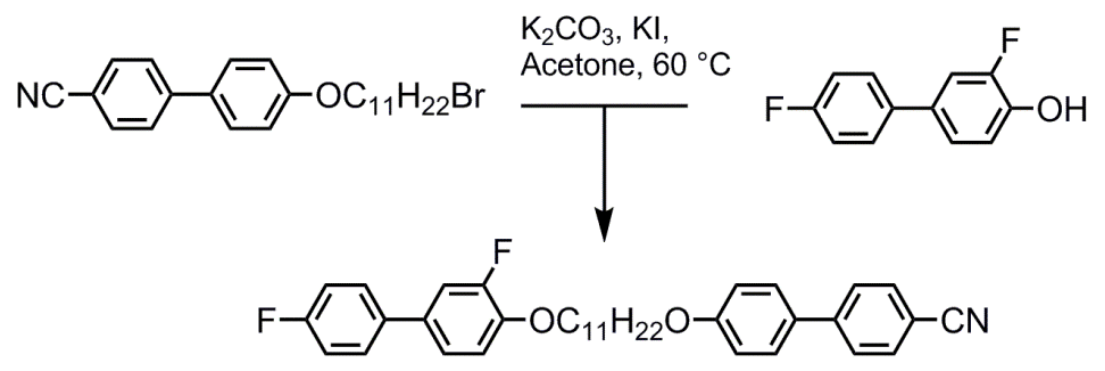

\section{4'-((11-((2,4'-difluoro-[1,1'-biphenyl]-4-yl)oxy)undecyl)oxy)-[1,1'-biphenyl]-4-carbonitrile (21)}

Quantities used: i15 (500 mg, $1.168 \mathrm{mmol})$, i8 (282 mg, $1.370 \mathrm{mmol}), \mathrm{K}_{2} \mathrm{CO}_{3}(500 \mathrm{mg}, 3.62 \mathrm{mmol}), \mathrm{KI}$ $(1 \mathrm{~g})$, acetone $(15 \mathrm{ml})$. The experimental procedure was as described in the synthesis of compound $\mathrm{i}$, with the title compound isolated via flash chromatography with DCM as the eluent followed by recrystalisation from ethanol.

Yield: $550 \mathrm{mg}(85 \%)$

${ }^{1} \mathrm{H}$ NMR $\left(\mathrm{CDCl}_{3}\right): 1.28-1.52\left(14 \mathrm{H}, \mathrm{m},-\mathrm{CH}_{2}-\left(\mathrm{CH}_{2}\right)_{7}-\mathrm{CH}_{2}-\right), 1.76-1.88\left(\mathrm{ArOCH}_{2}-\mathrm{CH}_{2}-\left(\mathrm{CH}_{2}\right)_{7}-\mathrm{CH}_{2}-\right.$ $\left.\mathrm{CH}_{2} \mathrm{OAr}\right), 3.99\left(2 \mathrm{H}, \mathrm{t}, \mathrm{J}=6.9 \mathrm{~Hz}, \mathrm{ArOCH}_{2}\right), 4.05\left(2 \mathrm{H}, \mathrm{t}, J=6.9 \mathrm{~Hz}, \mathrm{ArOCH}_{2}\right), 6.99(2 \mathrm{H}, \mathrm{ddd}, J=1.8 \mathrm{~Hz}$, $H=2.7 \mathrm{~Hz}, J=8.7 \mathrm{~Hz}, \operatorname{ArH}), 6.98(2 \mathrm{H}, \mathrm{m}, \mathrm{ArH}), 7.05-7.14(2 \mathrm{H}, \mathrm{m}, \mathrm{ArH}), 7.18-7.28(2 \mathrm{H}, \mathrm{m}, \mathrm{ArH})$, $7.43-7.48(2 \mathrm{H}, \mathrm{m}, \mathrm{ArH}), 7.51(2 \mathrm{H}, \mathrm{ddd}, J=1.8 \mathrm{~Hz}, H=2.7 \mathrm{~Hz}, J=8.7 \mathrm{~Hz}, \operatorname{ArH}), 7.62(2 \mathrm{H}$, ddd, J= 1.8 $\mathrm{Hz}, H=2.7 \mathrm{~Hz}, J=8.7 \mathrm{~Hz}, \operatorname{ArH}), 7.67(2 \mathrm{H}, \mathrm{ddd}, J=1.8 \mathrm{~Hz}, H=2.7 \mathrm{~Hz}, J=8.7 \mathrm{~Hz}, \operatorname{ArH})$. 
$\left.{ }^{13} \mathrm{C} \mathrm{NMR} \mathrm{(CDCl}\right): 25.87,25.98,29.16,29.28,29.29,29.43,29.46,29.48,68.11,69.48,109.95,114.67$ (d, J = 19.2 Hz), $114.96(\mathrm{~d}, J=1.9 \mathrm{~Hz}), 115.02,115.63(\mathrm{~d}, J=22.0 \mathrm{~Hz}), 119.09,122.40(\mathrm{~d}, J=2.9 \mathrm{~Hz}$ ), 127.00, $128.16(\mathrm{~d}, J=8.6 \mathrm{~Hz}), 128.26,131.17,132.51,133.25(\mathrm{~d}, J=6.7 \mathrm{~Hz}), 135.83(\mathrm{~m}), 145.22$, 146.47 (d, J = 10.5 Hz), 152.74 (d, J = 246.3 Hz), 159.75, 162.26 (d, J = 246.3 Hz)

$\left.{ }^{19} \mathrm{~F} \mathrm{NMR} \mathrm{(CDCl} 3\right):-134.04(1 \mathrm{~F}, \mathrm{dd}, J=8.7 \mathrm{~Hz}, J=11.6 \mathrm{~Hz}, \operatorname{ArF}),-115.6(1 \mathrm{~F}, \mathrm{tt}, J=5.8 \mathrm{~Hz}, J=8.7 \mathrm{~Hz}$, ArF).

FT-IR (cm-1): 721, 802, 827, 856, 999, 1041, 1128, 1217, 1365, 1435, 1492, 1600, 1739, 2222, 2852 , 2924, 2941, 2970, 3016

MS (ESI+): $592.2417\left(\mathrm{C}_{36} \mathrm{H}_{37} \mathrm{~F}_{2} \mathrm{NKO}_{2}, \mathrm{M}+\mathrm{K}\right), 576.2672\left(100 \%, \mathrm{C}_{36} \mathrm{H}_{37} \mathrm{~F}_{2} \mathrm{NNaO}_{2}, \mathrm{M}+\mathrm{Na}\right.$, Calc. for $\left.\mathrm{C}_{36} \mathrm{H}_{37} \mathrm{~F}_{2} \mathrm{NNaO}_{2} 576.2685\right)$

Assay (HPLC, C18, 230/265 nm): 99.5\% 
1. R. J. Mandle, E. J. Davis, S. A. Lobato, C. -C. A. Voll, S. J. Cowling and J. W. Goodby, PCCP, 2014, $16,6907-6915$.

2. R. J. Mandle, E. J. Davis, C. -C. A. Voll, D. J. Lewis, S. J. Cowling and j. W. Goodby, J. Mater. Chem. C, 2015, 3, $2380-2388$.

3. Gaussian 09, Revision D.01, M. J. Frisch, G. W. Trucks, H. B. Schlegel, G. E. Scuseria, M. A. Robb, J. R. Cheeseman, G. Scalmani, V. Barone, B. Mennucci, G. A. Petersson, H. Nakatsuji, M. Caricato, X. Li, H. P. Hratchian, A. F. Izmaylov, J. Bloino, G. Zheng, J. L. Sonnenberg, M. Hada, M. Ehara, K. Toyota, R. Fukuda, J. Hasegawa, M. Ishida, T. Nakajima, Y. Honda, O. Kitao, H. Nakai, T. Vreven, J. A. Montgomery, Jr., J. E. Peralta, F. Ogliaro, M. Bearpark, J. J. Heyd, E. Brothers, K. N. Kudin, V. N. Staroverov, R. Kobayashi, J. Normand, K. Raghavachari, A. Rendell, J. C. Burant, S. S. lyengar, J. Tomasi, M. Cossi, N. Rega, J. M. Millam, M. Klene, J. E. Knox, J. B. Cross, V. Bakken, C. Adamo, J. Jaramillo, R. Gomperts, R. E. Stratmann, O. Yazyev, A. J. Austin, R. Cammi, C. Pomelli, J. W. Ochterski, R. L. Martin, K. Morokuma, V. G. Zakrzewski, G. A. Voth, P. Salvador, J. J. Dannenberg, S. Dapprich, A. D. Daniels, Ö. Farkas, J. B. Foresman, J. V. Ortiz, J. Cioslowski, and D. J. Fox, Gaussian, Inc., Wallingford CT, 2009. 